\title{
Genome-Wide Study of the Tomato SIMLO Gene Family and Its Functional Characterization in Response to the Powdery Mildew Fungus Oidium neolycopersici
}

\author{
Zheng Zheng ${ }^{1+}$, Michela Appiano ${ }^{2+}$, Stefano Pavan ${ }^{3}$, Valentina Bracuto ${ }^{3}$, Luigi Ricciardi ${ }^{3}$, \\ Richard G. F. Visser ${ }^{2}$, Anne-Marie A. Wolters ${ }^{2}$ and Yuling Bai ${ }^{2 *}$ \\ ${ }^{1}$ Institute of Vegetables and Flowers, Chinese Academy of Agricultural Sciences, Beijing, China, ${ }^{2}$ Wageningen UR Plant \\ Breeding, Wageningen University and Research Centre, Wageningen, Netherlands, ${ }^{3}$ Section of Genetics and Plant Breeding, \\ Department of Plant, Soil and Food Science, University of Bari Aldo Moro, Bari, Italy
}

OPEN ACCESS

Edited by:

Ralph Panstruga

RWTH Aachen University, Germany

Reviewed by:

Ralph Hückelhoven,

Technische Universität München,

Germany

Thomas Debener,

Leibniz University of Hanover,

Germany

${ }^{*}$ Correspondence:

Yuling $\mathrm{Bai}$

bai.yuling@wur.n!

${ }^{\dagger}$ These authors have contributed equally to this work

Specialty section: This article was submitted to Plant Biotic Interactions,

a section of the journal Frontiers in Plant Science

Received: 23 December 2015 Accepted: 12 March 2016 Published: 06 April 2016

Citation:

Zheng Z, Appiano M, Pavan S,

Bracuto V, Ricciardi L, Visser RGF,

Wolters A-MA and Bai Y (2016)

Genome-Wide Study of the Tomato

SIMLO Gene Family and Its Functional

Characterization in Response to the

Powdery Mildew Fungus Oidium

neolycopersici.

Front. Plant Sci. 7:380

do: $10.3389 /$ fpls.2016.00380
The MLO (Mildew Locus O) gene family encodes plant-specific proteins containing seven transmembrane domains and likely acting in signal transduction in a calcium and calmodulin dependent manner. Some members of the MLO family are susceptibility factors toward fungi causing the powdery mildew disease. In tomato, for example, the loss-of-function of the MLO gene SIMLO1 leads to a particular form of powdery mildew resistance, called $\mathrm{O}-2$, which arrests almost completely fungal penetration. This type of penetration resistance is characterized by the apposition of papillae at the sites of plant-pathogen interaction. Other MLO homologs in Arabidopsis regulate root response to mechanical stimuli (AtMLO4 and AtMLO11) and pollen tube reception by the female gametophyte (AtMLO7). However, the role of most MLO genes remains unknown. In this work, we provide a genome-wide study of the tomato SIMLO gene family. Besides SIMLO1, other 15 SIMLO homologs were identified and characterized with respect to their structure, genomic organization, phylogenetic relationship, and expression profile. In addition, by analysis of transgenic plants, we demonstrated that simultaneous silencing of SIMLO1 and two of its closely related homologs, SIMLO5 and SIMLO8, confer higher level of resistance than the one associated with the ol-2 mutation. The outcome of this study provides evidence for functional redundancy among tomato homolog genes involved in powdery mildew susceptibility. Moreover, we developed a series of transgenic lines silenced for individual SIMLO homologs, which lay the foundation for further investigations aimed at assigning new biological functions to the $M L O$ gene family.

\section{Keywords: MLO gene family, tomato, susceptibility, powdery mildew disease}

\section{INTRODUCTION}

Many important crop species can be affected by the powdery mildew (PM) disease, resulting in great yield losses in agricultural settings. In barley, recessive loss-of-function mutations occurring in the HvMLO (Hordeum vulgare Mildew Resistance Locus $O$ ) gene confer resistance to all known isolates of the PM fungus Blumeria graminis f.sp hordei. Therefore, natural 
or induced mlo-mutant alleles are in use for about seven decades to introduce resistance in spring barley breeding programs (Jørgensen, 1992; Büschges et al., 1997; Reinstädler et al., 2010).

Biochemical analysis showed that the barley HvMLO protein contains seven transmembrane domains integral to the plasma membrane, with an extracellular amino-terminus and an intracellular carboxy-terminus. The latter harbors a calmodulinbinding domain likely involved in sensing calcium influxes into cells (Devoto et al., 1999). Although the domain structure of MLO proteins is related to that of metazoan G-protein coupled receptors (GPCRs), several studies could not confirm the role of MLO proteins as canonical GPCRs (Kim et al., 2002; Lorek et al., 2013). Despite further intensive efforts to explain the biochemical function of the HvMLO protein, its core activity remains elusive (Panstruga, 2005). However, HvMLO might be exploited by the fungus to impair vesicle-associated defense mechanism at plant-pathogen interaction sites, thus facilitating its penetration (Panstruga and Schulze-Lefert, 2003; Opalski et al., 2005; Miklis et al., 2007). This feature makes $H v M L O$ a typical representative of susceptibility genes (S-genes) (Miklis et al., 2007; van Schie and Takken, 2014).

The robustness of barley mlo-resistance, due to its non-racespecific spectrum and durability, led in the last years to an extensive quest for identification and functional characterization of the $M L O$ genes in other species affected by the PM disease. The search resulted in the identification of multiple $M L O$ gene families, ranging from 12 to 39 members in Arabidopsis, rice, grapevine, cucumber, apple, peach, woodland strawberry, tobacco, and soybean (Devoto et al., 2003; Feechan et al., 2008; Liu and Zhu, 2008; Shen et al., 2012; Zhou et al., 2013; Pessina et al., 2014; Appiano et al., 2015). Moreover, specific homologs were shown to play a major role in plant-pathogen interactions (Consonni et al., 2006).

A detailed phylogenetic analysis distinguished up to eight clades in which Angiosperm MLO proteins can be found (Feechan et al., 2008; Acevedo-Garcia et al., 2014; Pessina et al., 2014). The MLO homologs involved in the interaction with PM pathogens (Arabidopsis AtMLO2, AtMLO6, AtMLO12, tomato SIMLO1, pea Er1/PsMLO1, grapevine VvMLO3 and VvMLO4, tobacco NtMLO1, pepper CaMLO2, cucumber CsaMLO8, Lotus japonicus LjMLO1, and barrel clover MtMLO1) are grouped into clade V. On the other hand, all the known monocot MLO homologs acting as susceptibility factors (barley HvMLO, rice OsMLO3, and wheat TaMLO_A1 and TaMLO_B1) do not cluster in clade $\mathrm{V}$, but in clade IV, which is primarily but not exclusively represented by monocot MLO proteins. For example, grapevine VvMLO14, strawberry FvMLO17, and peach PpMLO12 belong also to clade IV (Elliott et al., 2002; Feechan et al., 2008; AcevedoGarcia et al., 2014; Pessina et al., 2014).

In Arabidopsis, the PM resistance conferred by the loss-offunction of AtMLO2 is incomplete and only mutations in all the three AtMLO homologs in clade $\mathrm{V}$ can completely prevent fungal entry (Consonni et al., 2006). In addition, more recent studies in Arabidopsis indicated that other members of the $M L O$ gene family play a role in different biological processes. The homologs AtMLO4 and AtMLO11 are together involved in root thigmomorphogenesis, i.e., root responses to mechanical stimuli
(Chen et al., 2009), while AtMLO7 regulates pollen tube reception from the synergid cells during fertilization (Kessler et al., 2010). The biological roles of other $M L O$ homologs still remain elusive.

Tomato (Solanum lycopersicum) is one of the most economically important vegetables in the world. It can be host of three PM species, namely Oidium neolycopersici, Oidium lycopersici, and Leveillula taurica (Seifi et al., 2014). Since 1996, when it was found that all the tomato cultivars were susceptible to $O$. neolycopersici, extensive researches were conducted by our group for sources of resistance (Seifi et al., 2014). An allele containing a 19 bp deletion in the coding region of the PM susceptibility gene SIMLO1 was found in a wild accession of $S$. lycopersicum var. cerasiforme. This mutant allele, named ol-2, was shown to confer recessively inherited broad-spectrum resistance to a series of isolates of O. neolycopersici (Bai et al., 2005, 2008). Through histological analysis, it was shown that its mechanism of resistance is based on the early abortion of fungal pathogenesis at the sites of attempted penetration (Bai et al., 2005). This type of penetration resistance is characterized by papillae apposition, the same as described also for the PM resistance in the Atmlo2 mutant of Arabidopsis (Consonni et al., 2006). Although papilla formation can significantly reduce fungal development at the host cell entry level, fungal penetration was not fully prevented in the ol-2 mutant (Bai et al., 2005).

In this study, we exploited tomato sequence information, derived from the tomato genome sequencing Heinz 1706 and the 150 tomato genome resequencing projects (Tomato Genome Consortium, 2012; The 100 Tomato Genome Sequencing Consortium et al., 2014), in order to identify tomato $M L O$ homologs (SlMLO). These were characterized with respect to (1) their genomic organization, (2) relation with $M L O$ homologs from other species, (3) occurrence of tissue-specific differentially spliced variants, (4) expression in different tissues in axenic condition and (5) upon inoculation with the powdery mildew pathogen $O$. neolycopersici. Finally, an RNAi-based reverse genetic approach was followed to investigate the possibility that SlMLO homologs other than SlMLO1 could play additional roles in the interaction with $O$. neolycopersici.

\section{RESULTS}

\section{In silico Identification and Sequencing of the Tomato SIMLO Gene Family}

A total of 17 tomato $M L O$-like loci were identified through BLAST interrogation of the tomato genomic sequence database (SGN), using AtMLO protein sequences as query. Two of them (referred to as Solyc09g18830 and Solyc09g18840 in the SGN database) were noticeably shorter than other predicted $M L O$ homologs and physically close to each other, suggesting they are different parts of the same gene (Table 1). Search in the tomato EST database and gene prediction analysis in the S. pimpinellifolium genome with the FGENESH software allowed identifying a hypothetical full-length $M L O$ transcript encompassing Solyc09g18830 and Solyc09g18840. PCR from leaf of the tomato cultivar Moneymaker (MM) confirmed the presence of this transcript, which was named SlMLO7 (Supplementary Figure 1). The other 15 predicted SlMLO genes 
TABLE 1 | Features of the SIMLO gene family as inferred by the Sol Genomics Network Database.

\begin{tabular}{|c|c|c|c|c|c|}
\hline $\begin{array}{l}\text { SGN locus } \\
\text { name }\end{array}$ & MLO gene & Chromosome & Position & ORF lenght (aa) & Introns \\
\hline Solyc04g049090 & SIMLO1 & 4 & SL2.40ch04:38700445..38705951 & 507 & 14 \\
\hline Solyc08g015870 & SIMLO2 & 8 & SL2.40ch08:6074040..6078983 & 504 & 13 \\
\hline Solyc06g010030 & SIMLO3 & 6 & SL2.40ch06:4786764..4792828 & 591 & 14 \\
\hline Solyc00g007200 & SIMLO4 & $2 ?$ & SL2.40ch00:6816892..6823417 & 554 & 14 \\
\hline Solyc03g095650 & SIMLO5 & 3 & SL2.40ch03:50279919..50288063 & 517 & 14 \\
\hline Solyc02g082430 & SIMLO6 & 2 & SL2.40ch02:40694608..40700995 & 553 & 14 \\
\hline $\begin{array}{l}\text { Solyc09g018830 } \\
\text { Solyc09g018840 }\end{array}$ & SIMLO7 & 9 & SL2.40ch09:17564555..17568214 & 270 & 10 \\
\hline Solyc11g069220 & SIMLO8 & 11 & SL2.40ch11:50939533..50946726 & 506 & 13 \\
\hline Solyc06g082820 & SIMLO9 & 6 & SL2.40ch06:44779673..44784035 & 511 & 13 \\
\hline Solyc02g083720 & SIMLO10 & 2 & SL2.40ch02:41596474..41602413 & 533 & 14 \\
\hline Solyc01g102520 & SIMLO11 & 1 & SL2.40ch01:83071860..83075439 & 475 & 13 \\
\hline Solyc08g067760 & SIMLO12 & 8 & SL2.40ch08:53957062..53962884 & 532 & 14 \\
\hline Solyc10g044510 & SIMLO13 & 10 & SL2.40ch10:22128868..22135940 & 558 & 14 \\
\hline Solyc07g063260 & SIMLO14 & 7 & SL2.40ch07:62995345..63002900 & 563 & 14 \\
\hline Solyc02g077570 & SIMLO15 & 2 & SL2.40ch02:37045094..37050486 & 375 & 10 \\
\hline Solyc06g010010 & SIMLO16 & 6 & SL2.40ch06:4699552..4706571 & 477 & 14 \\
\hline
\end{tabular}

TABLE 2 | Types of differentially spliced events observed in cloned SIMLO homologs from different tissues of the tomato cv. Moneymaker.

\begin{tabular}{|c|c|c|c|c|c|}
\hline \multirow[t]{2}{*}{ SIMLO } & \multirow[t]{2}{*}{ Plant tissue } & \multicolumn{4}{|c|}{ Type of alternative splicing } \\
\hline & & $\begin{array}{c}\text { Intron } \\
\text { retention }\end{array}$ & $\begin{array}{c}\text { Exon } \\
\text { skipping }\end{array}$ & $\begin{array}{l}\text { Alternative } 5^{\prime} \\
\text { splice site }\end{array}$ & $\begin{array}{l}\text { Alternative } 3^{\prime} \\
\text { splice site }\end{array}$ \\
\hline SIMLO1 & Flower & & & & $\sqrt{ }$ \\
\hline SIMLO5* & Fruit & $\sqrt{ }$ & & & \\
\hline SIMLO6 & Leaf & & & $\sqrt{ }$ & $\sqrt{ }$ \\
\hline SIMLO9 & Leaf & & $\sqrt{ }$ & & \\
\hline SIMLO11* & Root & $\sqrt{ }$ & & & \\
\hline SIMLO13 & Leaf & & $\sqrt{ }$ & & $\sqrt{ }$ \\
\hline SIMLO15 & Fruit & & $\sqrt{ }$ & $\sqrt{ }$ & \\
\hline SIMLO15* & Root & $\sqrt{ }$ & $\sqrt{ }$ & $\sqrt{ }$ & \\
\hline SIMLO15* & Flower & $\sqrt{ }$ & $\sqrt{ }$ & $\sqrt{ }$ & \\
\hline
\end{tabular}

The asterisk (*) indicates SIMLO transcripts that can be either incompletely spliced or alternatively spliced.

were named from SlMLO1 to SlMLO6, and from SlMLO8 to SlMLO16, as reported in Table 1. For all of them, information is available with respect to putative amino acid length and number of introns.

With the exception of SIMLO4, information on chromosomal localization could also be inferred (Table 1). Most SIMLO homologs are scattered throughout the tomato genome, thus suggesting that segmental duplication events have been a major source for the evolution of the SlMLO gene family. Exceptions are represented by two physical gene clusters, one containing SlMLO6, SlMLO10, and SlMLO15 on chromosome 2, and the other containing SlMLO3 and SlMLO16 on chromosome 6.

Sequence and expression of all the predicted SIMLO homologs were verified by PCR amplification of cDNAs derived from four different tissues (leaf, root, flower, and ripened fruit) of MM. All the SIMLO homologs could be amplified at least from one plant tissue. In total, 15 SlMLO homologs could be cloned from leaf (with the exception of SlMLO12), 10 from flower, nine from fruit and eight from root (Supplementary Table 1).

Sequence alignment of cloned SIMLO transcripts with corresponding SGN predicted coding sequence (CDS), derived from the cultivar Heinz 1706, revealed polymorphisms for SIMLO7, SIMLO8, SIMLO10, and SIMLO15 (Supplementary Figure 1). The $1339 \mathrm{bp}$ SlMLO7 cloned transcript corresponds to a short open reading frame (ORF) due to a stop codon at 137139 bp (Supplementary Figure 1). The SGN predicted CDS of SIMLO8 misses part of the third, seventh, eighth, and ninth exon present in the corresponding transcript cloned from MM leaf; compared to the SGN predicted CDS of SIMLO10, the transcript cloned from MM fruit contains a base change at the beginning of the fifth exon, which results in a stop codon (Supplementary Figure 1). Also the predicted ORF of SlMLO15 is shorter (375 aa) than the average ORF length of other SIMLOs (Table 1). The sequence cloned from MM leaf has a longer ORF (459 aa) compared to the predicted SGN sequence (Table 3A).

In other cases, sequence alignments of cloned SIMLO from the different tissues with their corresponding genomic regions showed various types of splice variants, consisting of intron retention, exon skipping and alternative $5^{\prime}$ and $3^{\prime}$ splice sites, according to the types of alternative splicing described by Keren et al. (2010) (Table 2 and Supplementary Figure 1).

\section{Characterization of Conserved Amino Acids and Motifs of the SIMLO Proteins}

To examine sequence features of the tomato SIMLO proteins, a multiple sequence alignment was performed using sequences obtained by the conceptual translation of transcripts cloned in different tissues. When no deviating transcripts were observed for a SIMLO gene, the sequence obtained from leaf was used for translation, with the exception of SIMLO12 which is the only homolog that was not cloned from leaf but from flower. 
TABLE 3A | Features and motifs distribution occurring in SIMLO proteins obtained from in silico translation of leaf, root, flower, and fruit transcripts of the tomato cv. Moneymaker.

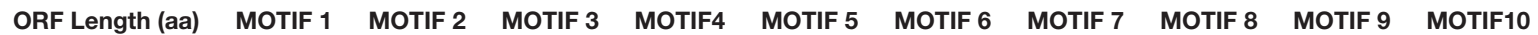

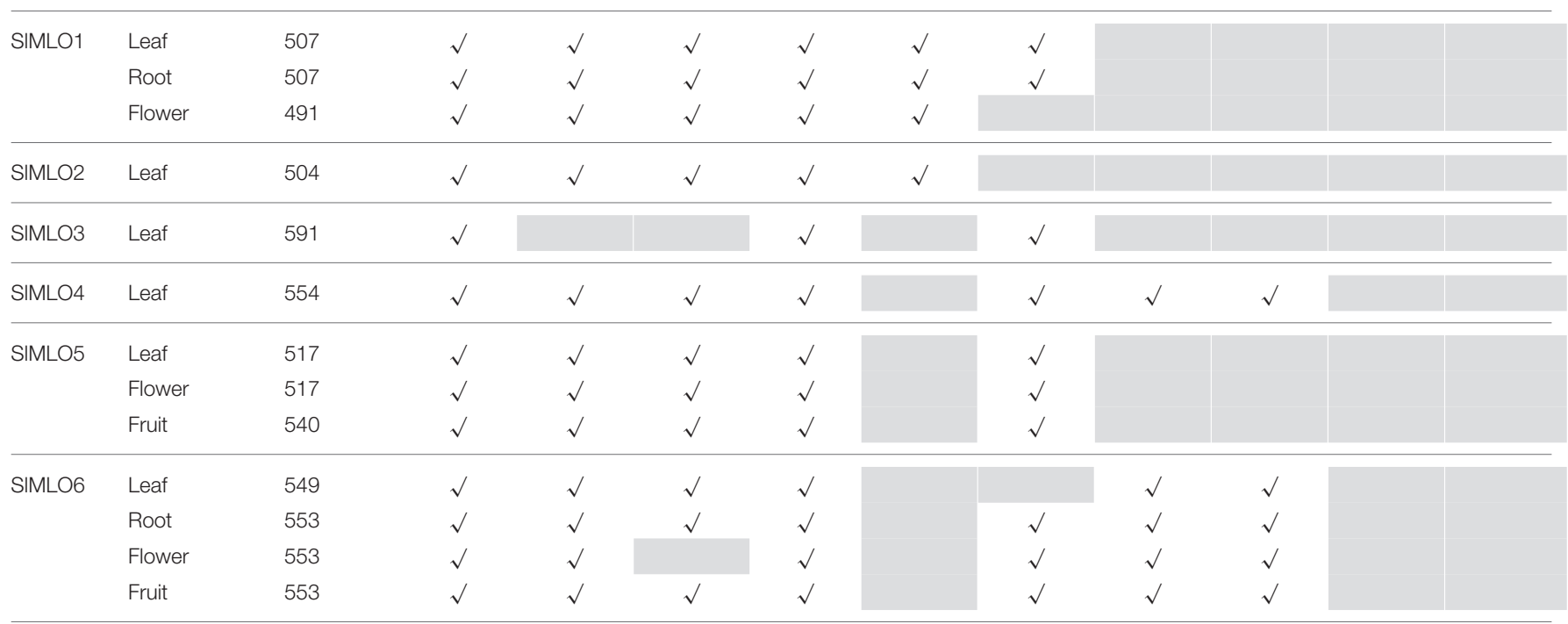

\begin{tabular}{llllllll|l|l|l|}
\hline SIMLO7 & Leaf & 61 & & & & & & \\
\hline SIMLO8 & Leaf & 561 & $\sqrt{ }$ & $\sqrt{ }$ & $\sqrt{ }$ & $\sqrt{ }$ & $\sqrt{ }$ & \\
\hline
\end{tabular}

\begin{tabular}{llllllllll}
\hline SIMLO9 & Leaf & 448 & $\sqrt{ }$ & & $\sqrt{ }$ & $\sqrt{ }$ & $\sqrt{ }$ & $\sqrt{ }$ & $\sqrt{ }$ \\
& Flower & 511 & $\sqrt{ }$ & $\sqrt{ }$ & $\sqrt{ }$ & $\sqrt{ }$ & $\sqrt{ }$ & $\sqrt{ }$ & $\sqrt{ }$ \\
& Fruit & 511 & $\sqrt{ }$ & $\sqrt{ }$ & $\sqrt{ }$ & $\sqrt{ }$ & $\sqrt{ }$ & $\sqrt{ }$ & $\sqrt{ }$ \\
& & & & &
\end{tabular}

\begin{tabular}{rlllllllll}
\hline SIMLO10 & Leaf & 533 & $\sqrt{ }$ & $\sqrt{ }$ & $\sqrt{ }$ & $\sqrt{ }$ & $\sqrt{ }$ & $\sqrt{ }$ & $\sqrt{ }$ \\
& Root & 533 & $\sqrt{ }$ & $\sqrt{ }$ & $\sqrt{ }$ & $\sqrt{ }$ & $\sqrt{ }$ & $\sqrt{ }$ & $\sqrt{ }$ \\
& Flower & 533 & $\sqrt{ }$ & $\sqrt{ }$ & $\sqrt{ }$ & $\sqrt{ }$ & $\sqrt{ }$ & $\sqrt{ }$ & $\sqrt{ }$ \\
& Fruit & 178 & & $\sqrt{ }$ & & & & & $\sqrt{ }$ \\
\hline
\end{tabular}

\begin{tabular}{|c|c|c|c|c|c|c|c|c|c|c|c|}
\hline \multirow[t]{4}{*}{ SIMLO11 } & Leaf & 475 & $\sqrt{ }$ & $\sqrt{ }$ & $\sqrt{ }$ & $\sqrt{ }$ & $\sqrt{ }$ & $\sqrt{ }$ & $\sqrt{ }$ & & \\
\hline & Root & 70 & & & & & & & & & \\
\hline & Flower & 475 & $\sqrt{ }$ & $\sqrt{ }$ & $\sqrt{ }$ & $\sqrt{ }$ & $\sqrt{ }$ & $\sqrt{ }$ & $\sqrt{ }$ & & \\
\hline & Fruit & 475 & $\sqrt{ }$ & $\sqrt{ }$ & $\sqrt{ }$ & $\sqrt{ }$ & $\sqrt{ }$ & $\sqrt{ }$ & $\sqrt{ }$ & & \\
\hline SIMLO12 & Flower & 532 & $\sqrt{ }$ & $\sqrt{ }$ & & $\sqrt{ }$ & & $\sqrt{ }$ & $\sqrt{ }$ & & \\
\hline \multirow[t]{3}{*}{ SIMLO13 } & Leaf & 63 & $\sqrt{ }$ & & & . & & & & & \\
\hline & Flower & 558 & $\sqrt{ }$ & $\sqrt{ }$ & & $\sqrt{ }$ & & $\sqrt{ }$ & & $\sqrt{ }$ & $\sqrt{ }$ \\
\hline & Fruit & 558 & $\sqrt{ }$ & $\sqrt{ }$ & & $\sqrt{ }$ & & $\sqrt{ }$ & & $\sqrt{ }$ & $\sqrt{ }$ \\
\hline SIMLO14 & Leaf & 563 & $\sqrt{ }$ & $\sqrt{ }$ & $\sqrt{ }$ & $\sqrt{ }$ & $\sqrt{ }$ & & & & \\
\hline SIMLO15 & Leaf & 459 & $\sqrt{ }$ & & $\sqrt{ }$ & & $\sqrt{ }$ & & $\sqrt{ }$ & & \\
\hline SIMLO16 & Leaf & 477 & $\sqrt{ }$ & & $\sqrt{ }$ & $\sqrt{ }$ & $\sqrt{ }$ & & & & \\
\hline
\end{tabular}

When no deviating transcripts are present for one SIMLO, the one from leaf has been used for motif analysis. Cells highlighted in gray indicate the absence of the corresponding motif. 
TABLE 3B | Features details of the consensus motifs reported in Table 3A as predicted by the MEME software package (http://meme-suite.org/tools/meme).

\begin{tabular}{|c|c|c|c|c|}
\hline & Sequence consensus & Width & e-value & Location \\
\hline MOTIF 1 & NAFQMAFFFWIWWEYGWKSCFWDNFIPIIIRLVMGVKVQWWCSYMTLPLYARVTQM & 56 & $6.5 e-1021$ & TM6 \\
\hline MOTIF 2 & PTWAVAMVCAVIVAISIFIERIIHKLGKWLKKKNKKALYEALEKIKEELMLLGFISLLLTVCQDYISQIC & 70 & $1.5 e-1076$ & TM1 \\
\hline MOTIF 3 & LLWIVCFFRQFYRSVNKSDYLTLRHGFIMAHCAPNNYNNFDYYMYRMREDDFDF & 54 & $3.9 e-840$ & $2 \mathrm{IC}$ \\
\hline MOTIF 4 & EGKVPFASYEALHQLHIFIFVLAVAHVLYCCTTMWLGMAKMRQWRAWEDETKT & 53 & $6.7 e-823$ & TM3 \\
\hline MOTIF 5 & VGISWYLWIFWLCLLLNINGWHSYFWIPFFPLILILLVGTKLEHIITQMAVEIAE & 56 & $1.0 \mathrm{e}-402$ & TM5 \\
\hline MOTIF 6 & GSTMKKSIFDENVRDALRKWHMTVKKRKKHKYDRSNTTRSNCPACSMAMDGPNHP & 55 & $8.8 \mathrm{e}-386$ & CaMBD \\
\hline MOTIF7 & HRYKTTGHSSRFQGYSDQEASDLENDPTTPMTRAEIATTHIDHDDTEIHVHIPQNGESTRNEDDFSFVKP & 70 & $2.50 \mathrm{E}-178$ & C-term \\
\hline MOTIF 8 & PPNVADTMLPCPPNNKDQAKEEEHCRHLGWYERRHLACNE & 40 & $6.30 \mathrm{E}-149$ & $2 \mathrm{EC}$ \\
\hline MOTIF9 & VNSSAVSSHFYPCSPPDNDMKSAITRDAIHGSSYSNHSTS & 40 & $1.90 \mathrm{E}-114$ & $2 \mathrm{EC}$ \\
\hline MOTIF 10 & SPCSSRGSFNHLDEKVLSNDHQEDCIVETTNQPGHELSFRNSEVLVTDAEEIVDDEADKIETLFELFQKT & 70 & 2.80E-89 & C-term \\
\hline
\end{tabular}

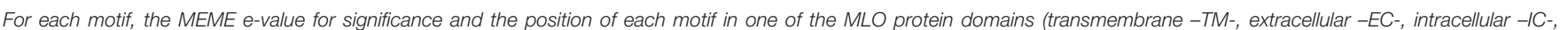
C-terminus -C-term-, calmodulin-binding-CaMBD-domain) is indicated.

The aligned amino acid sequences of the tomato SIMLO protein family showed a high degree of conservation (92\%) of the 30 amino acid residues previously described to be invariable throughout the whole MLO protein family (Supplementary Figure 2; Elliott et al., 2005).

Due to aberrant transcripts, the protein sequences of SIMLO7 and SIMLO13 in leaf, SIMLO11 in root, and SIMLO15 in root, flower and fruit, were severely truncated (Table 3A). The predicted ORF of SIMLO8 in leaf was longer than the one deriving from the SGN prediction, which is missing important domains of the translated MLO protein. The protein sequence of SlMLO9 in leaf was shorter (448 aa length) than the ones obtained from the other two tissues (512 aa length) and it is predicted to have five transmembrane (TM) domains, instead of seven as in fruit and flower (Table 3A).

Finally, the SIMLO protein family was also used as input to search for conserved motifs. Ten patterns of consecutive amino acids, having a length ranging from 40 to 70 and shared by at least three MLO sequences (Table 3B), were found. Interestingly, four of these motifs included transmembrane domains, while the others were located in the second intracellular and extracellular domains, in the C-terminus and in the calmodulin-binding domain. The motifs seven and nine were shared only by SIMLO4/SIMLO6 and SIMLO10/SIMLO13 respectively while the motif ten was only present in the amino acid sequences of SIMLO13 of root, flower, and fruit. Those motifs might indicate regions of peculiar importance for the specific function of these homologs.

\section{Phylogenetic Analysis of the Tomato SIMLO Protein Family}

A phylogenetic analysis was carried out in order to establish the relationships between SIMLO proteins and MLO proteins of other plant species (Arabidopsis AtMLO1-15, pea PsMLO1, Lotus japonicus LjMLO1, barrel clover MtMLO1, pepper CaMLO2, tobacco NtMLO1, cucumber CsaMLO8, apple MdMLO18 and MdMLO20, strawberry FvMLO13 and FvMLO15, peach PpMLO9 and PpMLO13, barley HvMLO, rice OsMLO3, and wheat TaMLOA1b and TaMLOB1a). The resulting tree contains eight different clades (Figure 1). These were named by Roman numerals from I to VIII, in accordance with previous studies performing phylogenetic analysis on the Arabidopsis and apple MLO protein families (Devoto et al., 2003; Pessina et al., 2014).

Five clades, namely clade I, II, III, V, and VI, contain both tomato and Arabidopsis homologs; clade IV contains only the monocot MLO homologs that were selected for this study; clade VII contains only SIMLO15 together with apple, peach and strawberry MLO proteins (MdMLO18, PpMLO9, and FvMLO15, respectively). No SIMLO homologs could be assigned to clade VIII, which only contains Rosaceae MLO homologs (Figure 1).

Three tomato MLO homologs, SIMLO3, SIMLO5, and SIMLO8, cluster together with SIMLO1 in clade V, containing all the known eudicot MLO homologs functionally related to powdery mildew susceptibility (AtMLO2, AtMLO6, AtMLO12, PsMlO1, LjMLO1, MtMlO1, CsaMlO8, NtMLO1, and CaMLO2; Figure 1; Elliott et al., 2005; Consonni et al., 2006; Bai et al., 2008; Pavan et al., 2009; Humphry et al., 2011; Várallyay et al., 2012; Zheng et al., 2013; Appiano et al., 2015; Berg et al., 2015).

The tomato homologs SIMLO4, SIMLO6, and SIMLO12 group in clade III together with AtMLO7, which regulates Arabidopsis pollen tube reception by the synergid cells, whereas SIMLO10, SIMLO13, and SIMLO14 are the closest tomato homologs to the root thigmomorphogenesis regulating proteins, AtMLO4 and AtMLO11, in clade I (Figure 1).

Finally, clade II includes four tomato SIMLO homologs (SIMLO2, SIMLO7, SIMLO9, and SIMLO11) together with three Arabidopsis proteins (AtMLO1, AtMLO13, and AtMLO15) and clade VI harbors only AtMLO3 and tomato SIMLO16 (Figure 1).

\section{Expression Profiles of SIMLO Homologs in Axenic Conditions and Upon Powdery Mildew Challenge}

The expression level of SIMLO genes was determined in four different tissues (leaf, root, flower, and ripened fruit). These were found to vary considerably among SIMLO genes, and it was not 


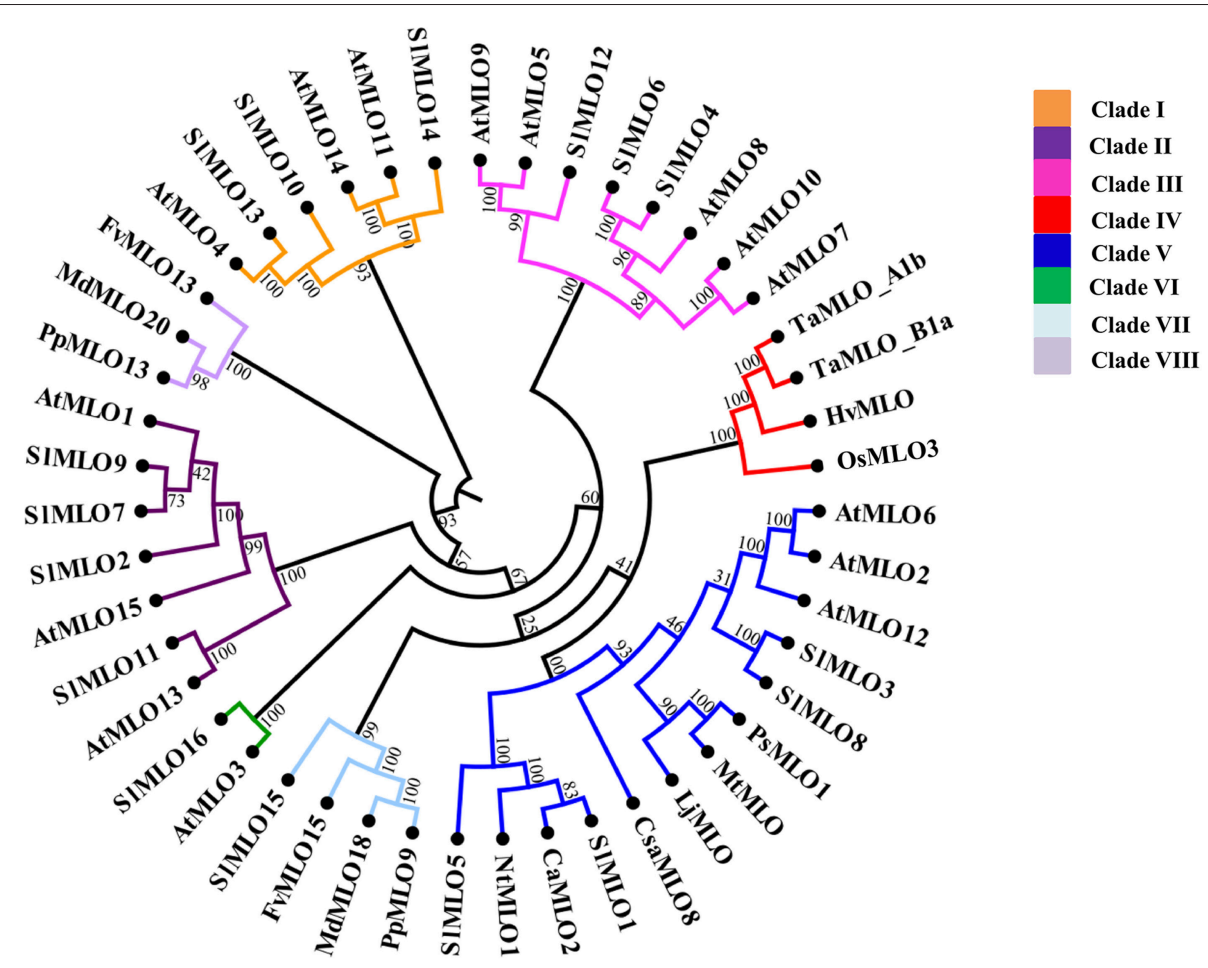

FIGURE 1 | Rooted circular cladogram showing the phylogenetic relationships of the tomato SIMLO proteins. A UPGMA-based tree comprises all the sequences of the MLO protein family of Arabidopsis (At) and tomato (SI). Individual sequences of apple (Md), tobacco (Nt), cucumber (Csa), pea (Ps), Lotus japonicus (Lj), barrel clover (Mt), pepper (Ca), barley (Hv), rice (Os), and wheat (Ta) are included. Numbers on each node represent bootstrap values based on 100 replicates. Phylogenetic clades are designated with colors and Roman numbers according to the position of AtMLO homologs and apple MdMLO, as indicated by Pessina et al. (2014). The tomato SIMLO protein sequences used for this tree derived all from the translation of the transcripts cloned from leaf of the cv. Moneymaker, except for SIMLO12, which corresponds to the translated sequence of flower. Accession numbers of the sequences used, other than tomato SIMLO, are listed in Supplementary Table 2.

possible to assign clade-specific expression patterns (Figure 2). Concerning clade V, SIMLO5 and SIMLO8 were found to be characterized by very low expression levels in all the tissues. Interestingly, SIMLO1 was found to be less expressed in leaves compared to flowers. Our results are supported by the collection of RNA-seq data, as shown by the FPKM (fragments per kilobase of exon per million fragments mapped) values for the four tissues under investigation of each homolog represented into graphs of Supplementary Figure 3.

Next, we investigated the expression profile of the SIMLO gene family in response to $O$. neolycopersici, using L33 as a reference gene (Figure 3). SlMLO1 expression significantly increased at 6 and $10 \mathrm{~h}$ after pathogen challenge. No other SIMLO homolog in clade V (SlMLO3, SIMLO5, SlMLO8) showed pathogendependent up-regulation.

On the other hand, a significant upregulation in response to O. neolycopersici was observed for SIMLO homologs outside clade V, namely SIMLO2, SIMLO4, SIMLO7, SIMLO10, SIMLO13, SlMLO14, and SIMLO16. In particular, the expression of SIMLO4 and SIMLO14 at $10 \mathrm{~h}$ after inoculation was comparable to the one of SIMLO1, and $\sim$ four-fold and $\sim$ three-fold higher than the one of control plants, respectively.

Similar results were obtained repeating the expression analysis using Ef $1 \alpha$ as reference gene (Supplementary Figure 4).
In order to confirm the strong up-regulation of the above mentioned genes, a second inoculation experiment was carried out, sampling leaf tissues at the same time points $(0,6$, and 10 hpi). The results presented in Supplementary Figure 5 indicate that indeed SlMLO1, SlMLO4, and SlMLO14 show a statistically significant up-regulated expression due to the O. neolycopersici challenge. The slight down-regulated expression of SlMLO3 observed after the first pathogen inoculation was not confirmed in the second experiment.

\section{Functional Characterization of Clade V SIMLO Homologs}

Based on their relatedness with eudicot $M L O$ homologs predisposing to PM susceptibility, including SIMLO1, the newly identified SIMLO homologs in clade V (SIMLO3, SIMLO5, and SlMLO8, Figure 1) were further investigated with respect to their role in the interaction with $O$. neolycopersici. Therefore, specific RNAi silencing constructs for these three homologs were developed, which were used to transform the susceptible cultivar Moneymaker (MM) (Supplementary Figure 6 and Supplementary Table 3). A silencing construct targeting SlMLO1 was included as control, which was expected to lead to a resistant phenotype. 


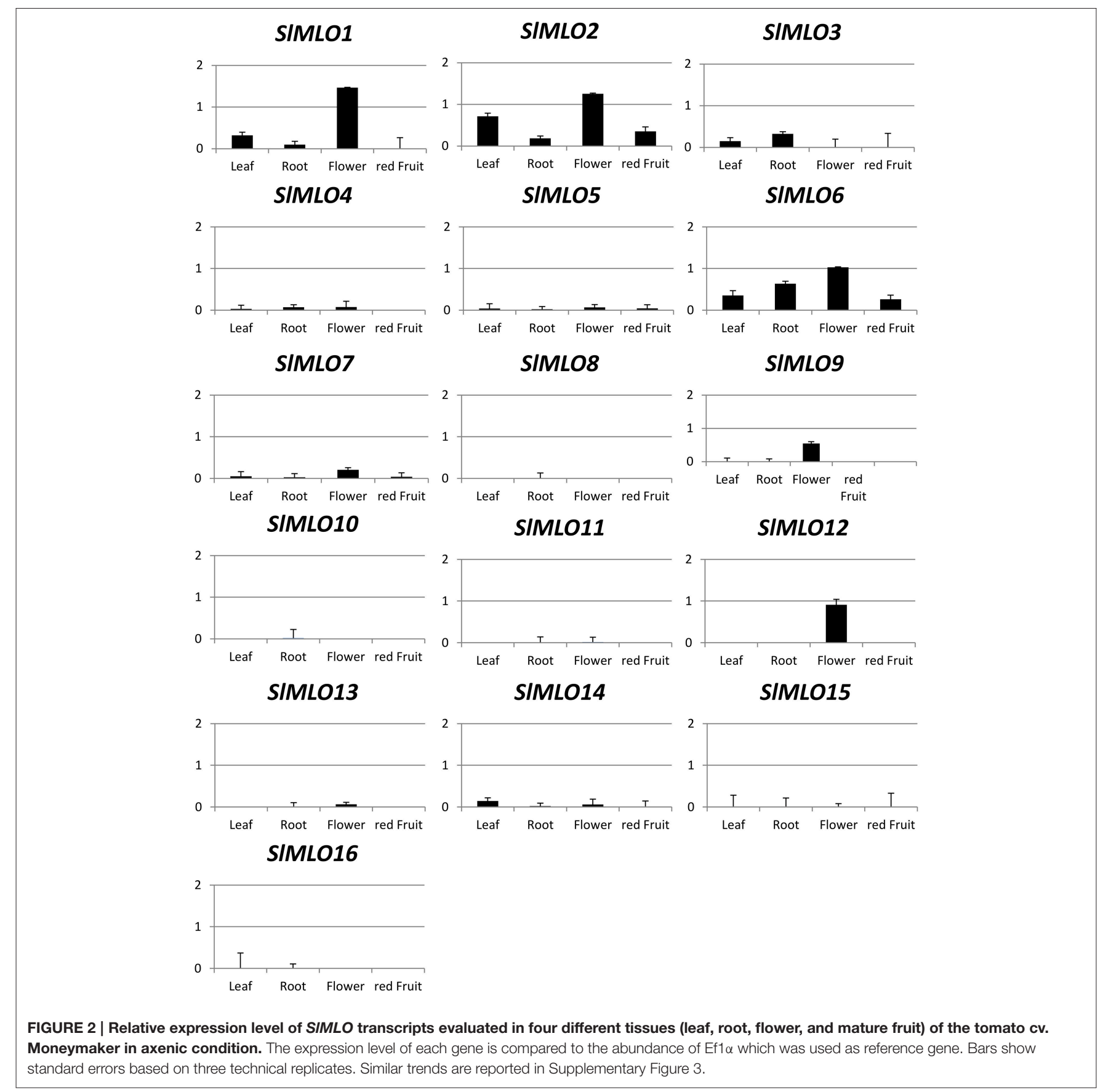

Ten to $20 \mathrm{~T}_{1}$ plants were obtained for each silencing construct. The expression of the target genes was assessed by means of real-time qPCR (Supplementary Figure 7 ) and $\mathrm{T}_{1}$ plants with a reduced level of expression of the target gene were allowed to self-pollinate to develop $\mathrm{T}_{2}$ families. In total, two independent $\mathrm{T}_{2}$ families (each segregating for the presence of the silencing construct) were developed for SIMLO1 and SIMLO8, and three were obtained for SIMLO3 and SlMLO5. Transgenic individuals of each family were further assessed for the silencing levels of target genes and other clade $\mathrm{V}$ homologs. This revealed successful silencing of each target genes and no unwanted co-silencing in transgenic RNAi::SlMLO3, SlMLO5, and SIMLO8 individuals (Figures 4B-D). Conversely, $\mathrm{T}_{2}$ transgenic plants of two $\mathrm{T}_{2}$ families carrying the RNAi::SIMLO1 silencing construct were characterized by the simultaneous silencing of SIMLO1, SIMLO5, and SIMLO8 (Figure 4A and Supplementary Figure 8).

As expected, $\mathrm{T}_{2}$ progenies carrying the RNAi::SlMLO1 construct segregated for $\mathrm{PM}$ resistance: $\mathrm{T}_{2}$ plants carrying the silencing construct $\left[\mathrm{T}_{2} \_S I M L O 1 \_\mathrm{NPT}(+)\right]$ were resistant, whereas non-transgenic plants [ $\left.\mathrm{T}_{2} \_S l M L O 1 \_\mathrm{NPT}(-)\right]$ were susceptible as MM (Figure 5A). In contrast, all $\mathrm{T}_{2}$ progenies segregating for SIMLO3, SIMLO5, and SIMLO8 silencing 


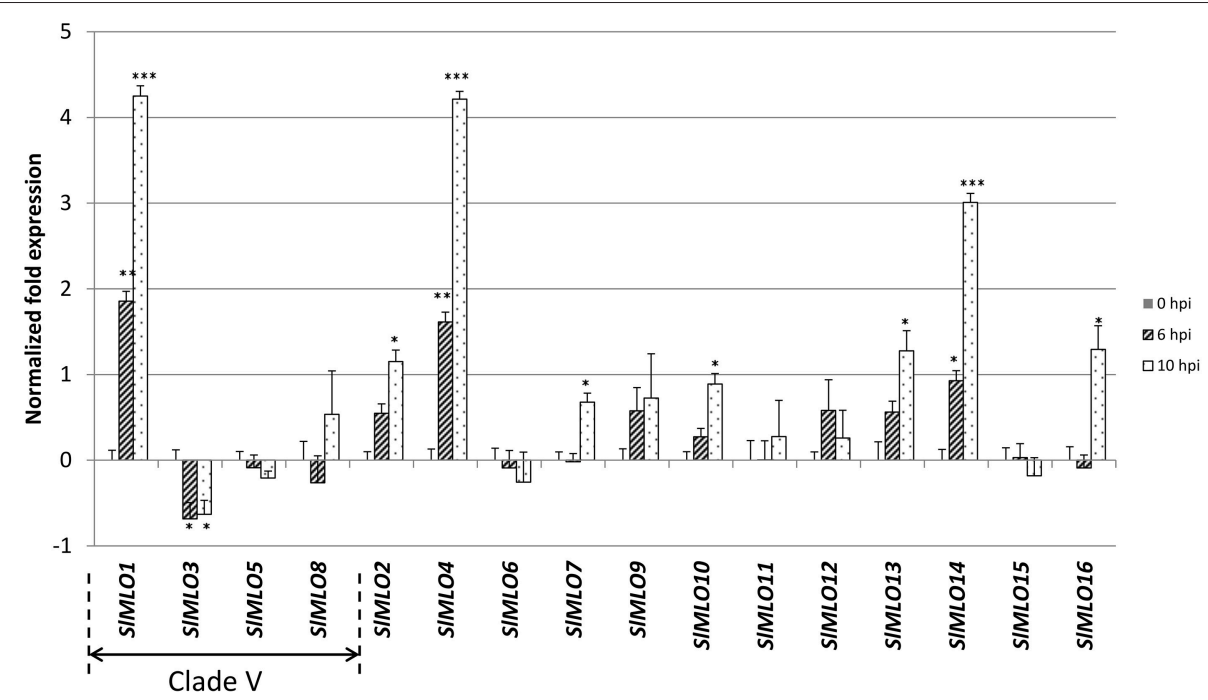

FIGURE 3 | Relative expression level of the SIMLO gene family in response to O. neolycopersici inoculation. Samples were collected at 0, 6, and $10 \mathrm{~h}$ after inoculation (hpi). Transcript abundance of each SIMLO homolog was normalized against the transcription level of the $60 S$ ribosomal protein $L 33$ used as reference gene. Bars show standard errors based on four biological replicates. Asterisks refer to significant differences with respect to non-inoculated plants ( 0 hpi), inferred by mean comparisons with a Student's $t$-test $\left({ }^{\star} p<0.05,{ }^{* \star} p<0.01,{ }^{* \star *} p<0.001\right)$. The SIMLO genes harbored in clade V, based on the phylogenetic tree of Figure 1 , are indicated by an arrow spanning their corresponding bars. Similar results were obtained by using the elongation factor Ef1 $\alpha$ as housekeeping gene (Supplementary Figure 4).
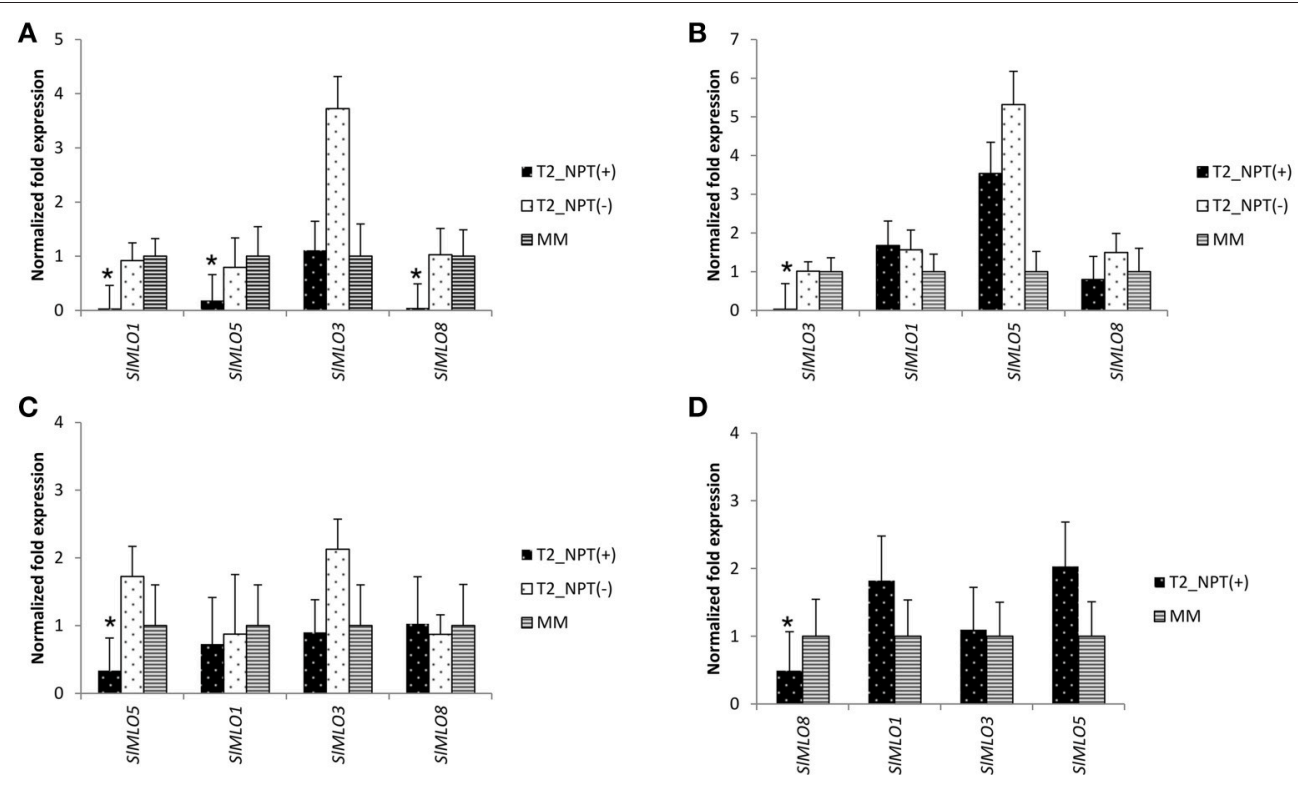

FIGURE 4 | Evaluation of the silencing effect of the RNAi constructs designed to target SIMLO1, SIMLO3, SIMLO5, and SIMLO8 in segregating $T_{2}$ families of the tomato cv. Moneymaker. Panels (A-D) show the expressions of clade V SIMLO homologs in plants of $\mathrm{T}_{2}$ families, derived from different transformation events and segregating for the presence [T 2_NPT(+)] or absence $\pi_{2}$ NPT(-)] of the RNAi::SIMLO1, RNAi::SIMLO3, RNAi::SLMLO5, and RNAi::SIMLO8 constructs, respectively. In (A) bars and standard errors refer to eight plants $T_{2} \_N P T(+)$ and four plants $T_{2} \_N P T(-)$ of two $T_{2}$ families and four Moneymaker (MM) plants. In (B) bars and standard errors refer to ten plants $T_{2}$ NPT( $(+)$ and five plants $T_{2}$ NPT(-) of three $T_{2}$ families and four MM individuals. In (C) bars and standard errors refer to ten plants $\mathrm{T}_{2} \mathrm{NPT}(+)$ and five plants $\mathrm{T}_{2}$ NPT(-) of three $\mathrm{T}_{2}$ families and four MM individuals. In (D) bars and standard errors refer to $10 T_{2}$ NPT (+) of two $T_{2}$ families and four MM individuals.

constructs visually appeared to be fully susceptible to $O$. neolycopersici (Figure 5A). The quantification of disease severity on these lines using real-time $\mathrm{qPCR}$ supported phenotypic observations, as no significant difference was found between $\mathrm{T}_{2} \_S l M L O 3 \_\mathrm{NPT}(+), \mathrm{T}_{2} S S I M L O 5 \_\mathrm{NPT}(+)$, $\mathrm{T}_{2} \_$SlMLO8_NPT $(+)$plants, and MM (Figure 5B and 


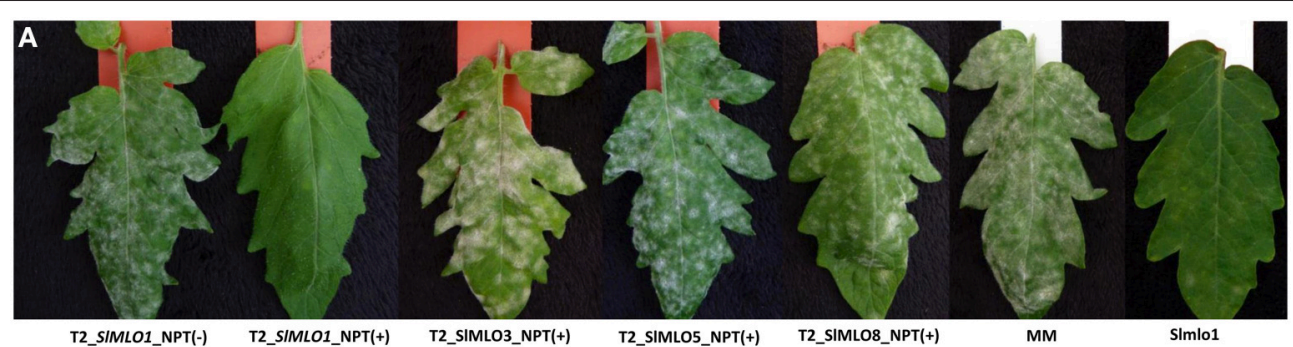

B

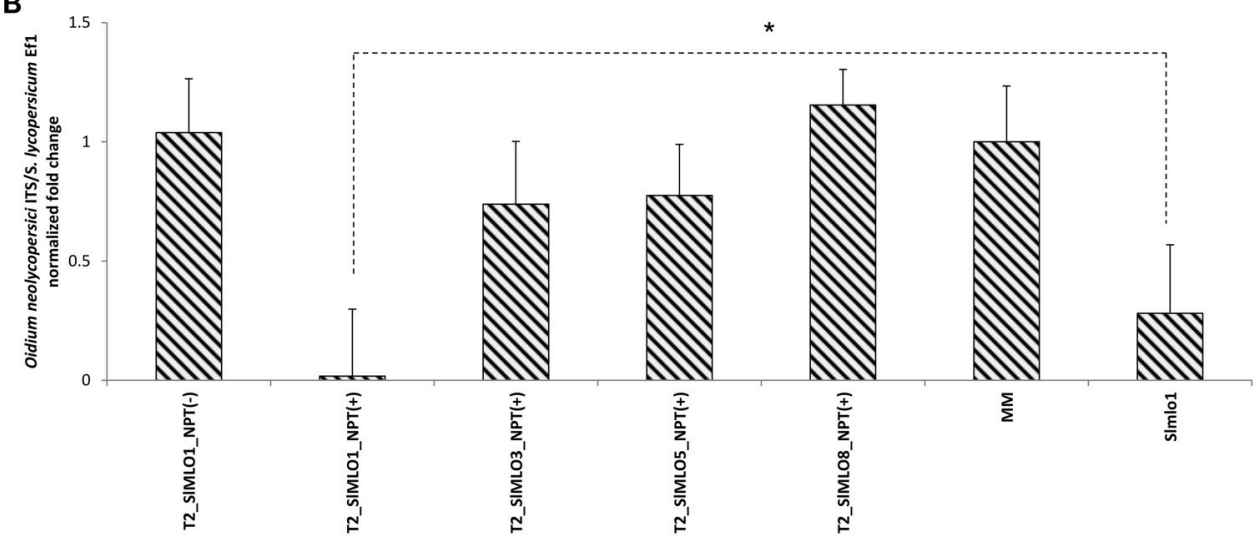

FIGURE 5 | Powdery mildew evaluation on plants of segregating $T_{2}$ families obtained with silencing constructs targeting SIMLO genes to attest their involvement in O. neolycopersici susceptibility. Panel (A) shows the phenotypic evaluation of the powdery mildew growth on leaves of different $T_{2}$ individuals that have been evaluated for the (from left to right) absence of the RNAi::SIMLO1, presence of the RNAi::SIMLO1, presence of the RNAi::SIMLO3, presence of the RNAi::SIMLO5, and presence of the RNAi::SIMLO8 silencing constructs, followed by one individual of the cv Moneymaker (MM) and one of the SImlo1 line carrying a loss-of-function mutation in the SIMLO1 gene. Panel (B) shows the relative quantification of the ratio between Oidium neolycopersici and plant gDNAs in transgenic individuals [NPT(+)] and not transgenic individuals [NPT(-)] segregating in $\mathrm{T}_{2}$ families obtained with the silencing constructs above described. Bars and standard errors refer to (from left to right) four individuals of two independent $T_{2}$ families not carrying the RNAi::SIMLO1, eight individuals of the same two $T_{2}$ families carrying the RNAi::SIMLO1, 18 individuals of three independent $T_{2}$ segregating families carrying the RNAi::SIMLO3 construct, 18 individuals of three independent $T_{2}$ segregating families carrying the RNAi::SIMLO5 construct and 20 individuals of two $T_{2}$ segregating families carrying the RNAi::SIMLO8 construct, next to 10 MM plants and 10 plants of the SImlo1 line. The asterisk refers to the significant difference in susceptibility between individuals of the T2_SIMLO1_NPT(+) and SImlo1, inferred by mean comparisons with a Student's $t$-test $\left({ }^{*} p<0.05\right)$.

Supplementary Figure 9). For each $\mathrm{T}_{2}$ family, transgenic and non-transgenic plants were phenotypically indistinguishable.

The Slmlo1 line, harboring a loss-of-function mutation in the SlMLO1 gene (Bai et al., 2008), is resistant to PM, however lower leaves displayed PM symptoms (Figure 5A). Compared to the plants of the Slmlo1 line, RNAi plants carrying the RNAi::SIMLO1 construct [T2_SlMLO1_NPT(+) plants] showed no PM symptom and also a significantly lower amount of fungal biomass (Figure 5B and Supplementary Figure 9A). Therefore, further microscopic observations were carried out to study the fungal growth on the Slmlo1 line and $\mathrm{T}_{2} \_$SlMLO1_NPT(+) plants.

Since the two $\mathrm{T}_{2}$ families carrying the RNAi::SlMLO1 construct showed no difference with respect to the level of reduced expression of the SIMLO homologs and fungal biomass quantification (Supplementary Figures 8, 9), we used one $\mathrm{T}_{2}$ family for microscopic study. Compared to MM, fungal growth was significantly reduced in both Slmlol and $\mathrm{T}_{2}$ RNAi::SlMLO1_NPT(+) individuals due to the formation of a papilla beneath the appressorium (Figure 6). Interestingly, the rate of papilla formation in $\mathrm{T}_{2} \_$RNAi::SlMLO1_NPT $(+)$
(93.3\% of the infection units) was significantly higher than in Slmlo1 (64.4\% of the infection units; Table 4). In some cases, O. neolycopersici was still able to penetrate epidermal cells and form haustoria with a rate of $48.9 \%$ in Slmlo1 and $30 \%$ in $\mathrm{T}_{2} \_$RNAi::SlMLO1_NPT(+) (Table 4 and Figure 6). The general development of the spores on the two genotypes was strikingly different: while on the Slmlo1 line the fungus could produce mostly up to two secondary hyphae (in $36.7 \%$ of the total infection units), on $\mathrm{T}_{2} \_\mathrm{RNAi}:$ SIMLO1_NPT(+) individuals fungal growth was significantly reduced after producing a germination tube (Table 4 and Figure 6).

\section{DISCUSSION}

\section{Structure and Evolution of the SIMLO Gene Family}

In this study, we followed an in silico approach to assign 16 homologs to the tomato $M L O$ gene family. This is consistent with the results of previous studies reporting the $M L O$ gene families of several diploid species made of a number of homologs variable from 13 to 21 (Devoto et al., 2003; Feechan et al., 2008; Liu and 
TABLE 4 | Development of Oidium neolycopersici growth on the susceptible genotype Moneymaker and on the two resistant genotypes, SImlo1 carrying a loss-of-function SIMLO1 gene and plants of a $T_{2}$ family selected to carry the RNAi::SIMLO1 silencing construct which can effectively silence SIMLO1, SIMLO5, and SIMLO8.

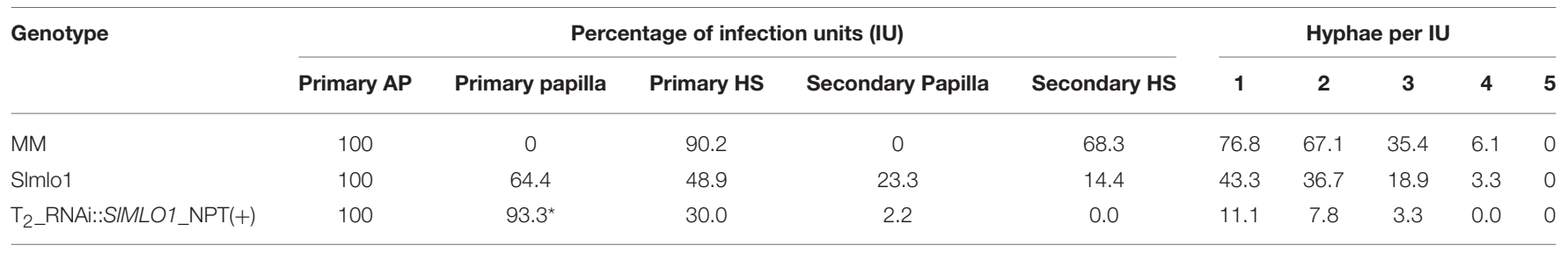

AP, appressorium; HS, haustorium; * $p<0.05$ compared to SImlo1.

Zhu, 2008; Shen et al., 2012; Pessina et al., 2014; Schouten et al., 2014; Appiano et al., 2015). This suggests that a similar number of $M L O$ homologs is likely to be retrieved in future genome-wide investigations involving diploid eudicot species.

Information on chromosomal localization was available for all the SIMLO homologs with the exception of SIMLO4. However, potato and tomato genomes are highly syntenic (Tomato Genome Consortium, 2012) and the closest SlMLO4 homolog in potato (Sotub02g007200) is positioned on chromosome 2, thus suggesting that SlMLO4 is also located on tomato chromosome 2.

Cloning of the SIMLO gene family from different tissues of the cultivar MM revealed the occurrence of transcripts deviating from predictions available at the SGN database, indicating that, despite the efforts of the tomato resequencing project, the assembly of genomic regions and the prediction of certain loci are not correct yet. Moreover, several cases of differentially spliced variants among plant tissues were observed, mostly due to intron retention and exon skipping, as it is in the case of SlMLO5, SlMLO9, SlMLO11, SlMLO13, and SlMLO15. Due to the method used in this study to amplify the SIMLO homologs, we cannot exclude that the intron retention is the result of the amplification of non-mature mRNA. However, intron retention was previously reported to be a very common type of alternative splicing in Arabidopsis and rice (Ner-Gaon et al., 2007). There is also a well-documented evidence indicating organ-specific regulation of alternative splicing in plants (Palusa et al., 2007). More studies need to be performed to unravel its complexity and functional significance. Certainly, alternative forms of splicing, such as the ones found in this study, can lead to aberrant mRNA isoforms that cause the loss-of-function of a $M L O$ gene. An example is reported by a recent study conducted by Berg et al. (2015) in cucumber. They show that the integration of a transposable element in the genomic region of the CsaMLO8 leads to an aberrant splicing that causes the lossof-function of this susceptibility gene in a resistant cucumber genotype.

The identification of protein motifs conserved in transmembrane domains of specific SIMLO homologs (Tables 3A,B) corroborates previous findings in Solanaceae plant species (Appiano et al., 2015). This indicates that transmembrane domains, which are thought to provide a common scaffold invariable for the whole MLO family (Devoto et al., 1999), might also be involved in conferring specific functions to MLO homologs. Future functional studies of targeted mutagenesis of transmembrane MLO protein regions can help to unravel their actual role.

All the SIMLO proteins were found to group in six phylogenetic clades together with other eudicot MLO homologs, including the complete Arabidopsis AtMLO family and certain members of the apple, peach and strawberry MLO family. No SIMLO homolog could be assigned to clade IV, previously shown to contain monocot MLO homologs and a few eudicot homologs (grapevine VvMLO14, strawberry FvMLO17, and peach PpMLO12) (Feechan et al., 2008; Pessina et al., 2014).

Based on their sequence relatedness with Arabidopsis AtMLO proteins of known function, it is logical to argue that one or more of the tomato SIMLO homologs in clade III and clade I could regulate the processes of root response to mechanical stimuli and pollen tube reception, respectively. The RNAi silenced lines of several SIMLO homologs generated in this study could be useful to assign new functions to MLO proteins which have gone unnoticed by the evaluation of the available panel of Arabidopsis Atmlo mutants.

\section{Possible Pleiotropic Effects and Co-functioning of SIMLO Homologs}

RNA-seq data, RT-PCR and real-time qPCR of the SlMLO gene family confirmed the expression of all the 16 SlMLO homologs. Often, it was possible to detect high level of transcript of the same SIMLO homolog in more than one of the four tissues under study (leaf, root, flower, and mature fruit). This is in line with the findings of the previous study of Chen et al. (2006), investigating the expression pattern of the Arabidopsis AtMLO gene family in several tissues. Overall, this body of evidence suggest that: (a) different $M L O$ homologs may have synergistic or antagonistic roles in regulating the same biological process; (b) $M L O$ homologs may have pleiotropic effects on different biological processes. Co-functioning between $M L O$ homologs has been demonstrated to occur in Arabidopsis, where different AtMLO genes co-participate in the same tissue to determine powdery mildew susceptibility and root response to mechanical stimuli (Consonni et al., 2006; Chen et al., 2009). A yet unidentified additional biological function could be hypothesized for the SlMLO1, previously shown to act as a susceptibility gene toward $O$. neolycopersici (Pavan et al., 2009). This gene was found to exhibit its strongest expression level in tomato flower and moderate expression in root, 

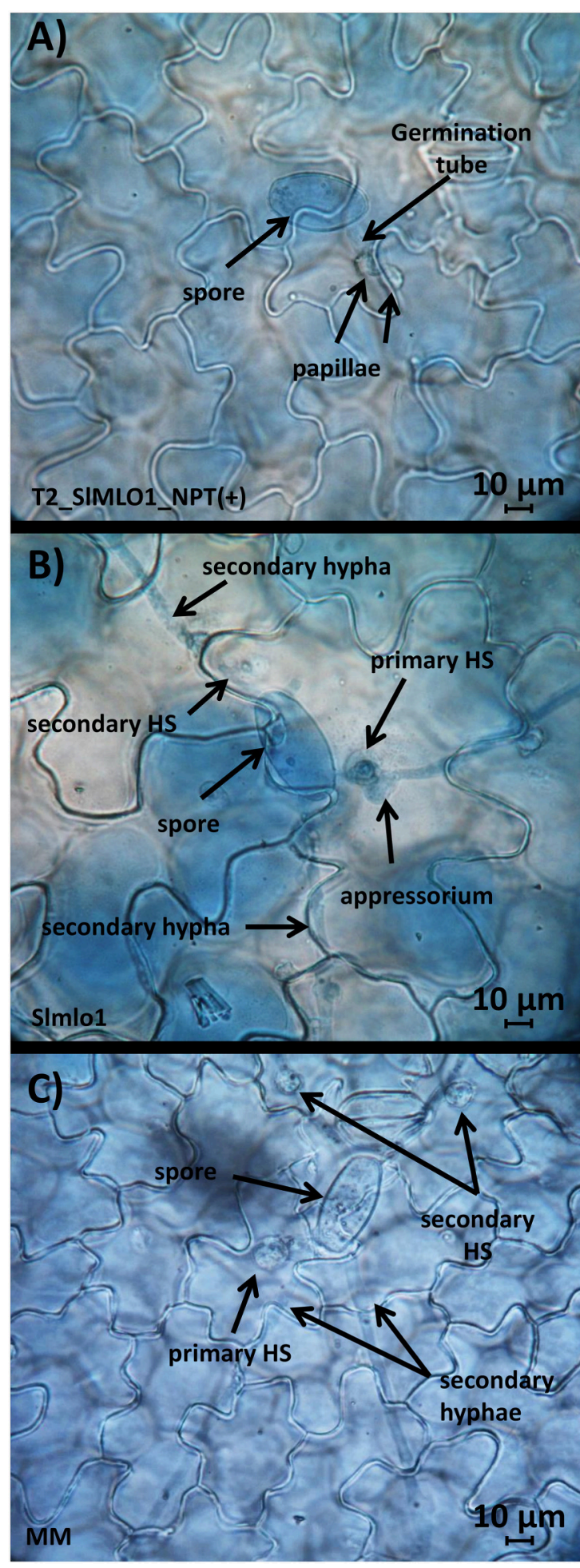

FIGURE 6 | Effect of the silencing of SIML01, SIMLO5, and SIMLO8 in tomato cv Moneymaker background compared with the SImlo1 line harboring a loss-of-function of the SIMLO1 gene. Panel (A) refers to a transgenic plant carrying the RNAi::SIMLO1 construct, Panel (B) a plant of the SImlo1 line and (C) a plant of the tomato cv. Moneymaker. Panels (A-C) show fungal structures (spores, germination tube, appressorium, haustorium -HS-, and hyphae) and the plant cellular reaction of papilla apposition at the sites of fungal penetration. two tissues which are less or not attacked by the fungus, respectively. Moreover, additional biological roles for SIMLO1 would explain why this gene has not been excluded from evolution, despite promoting susceptibility to PM pathogen. Interestingly, evidence shows that the SlMLO1 orthologs in barley and Arabidopsis are involved in the interaction with pathogens other than powdery mildews, such as necrotrophs and hemibiotroph (Jarosch et al., 1999; Kumar et al., 2001; Consonni et al., 2006). Thus, it is worthwhile to test the RNAi::SlMLO1 plants with more pathogens to broaden its role in plant-pathogen interactions.

\section{SIMLO Homologs Involved in Powdery Mildew Susceptibility}

In this study, we mainly focused on the SIMLO genes grouped in the clade $\mathrm{V}$ containing all the $M L O$ homologs associated with PM susceptibility in eudicots. The presence of multiple tomato homologs in clade $\mathrm{V}$ is in accordance with the existence of three Arabidopsis proteins (AtMLO2, AtMLO6, and AtMLO12) associated with increased fungal penetration (Consonni et al., 2006).

We showed that tomato SlMLO3, SlMLO5, and SlMLO8, differently from SlMLO1, do not increase their expression upon $O$. neolycopersici challenge. Furthermore, strong silencing of the same homologs in a susceptible tomato background (Moneymaker) did not result in a significant reduction of disease symptoms (Figures 3-5).

Plants transformed with a construct meant to silence SlMLO1 showed co-silencing of SIMLO5 and SlMLO8, due to sequence relatedness between these genes (Figure 4). Interestingly, these plants were also significantly more resistant than plants of the Slmlo1 line (Figure 5). Since the Slmlo1 line is only a $\mathrm{BC}_{3} \mathrm{~S}_{2}$ line carrying the Slmlo1mutation (the ol-2 gene) in MM background, we cannot fully exclude background effects from the ol-2 donor, the resistant line LC-95 of S. lycopersicum var. cerasiforme, which might add to partial susceptibility phenotype of the Slmlo1 line. On the other hand, our scenario is reminiscent of the one reported in Arabidopsis, where Atmlo2 single mutant displays partial PM resistance, whereas Atmlo2/Atmlo6/Atmlo12 triple mutant is fully resistant (Consonni et al., 2006). Also in grape, more than one $V v M L O$ genes are involved in susceptibility to powdery mildew (Feechan et al., 2008, 2013). Taken together with the knowledge of functional redundancy in Arabidopsis and grape, our data suggest that in tomato SlMLO1, SlMLO5, and SlMLO8 are functionally redundant as PM susceptibility factors with $S I M L O 1$ playing a major role. Our results showed that the contribution of SIMLO5 and SIMLO8 is too small to be observed with an RNAi approach silencing individual genes, but a complementation experiment using the Slmlo1 line could be more suitable to observe their minor role.

It cannot be excluded yet that the other clade $\mathrm{V}$ tomato homolog, SlMLO3, is also involved in plant-pathogen interactions. However, it is worthwhile to notice that the SIMLO3 protein is missing three of the six motifs contained in SIMLO1, two of which are also present in SIMLO5 and SIMLO8 (Table 3B). The motif three in Table 3B is located in the second 
intracellular domain, which is known to be involved together with the third intracellular domain in the protein functionality (Elliott et al., 2005). This would suggest that SlMLO3 might miss important features to be fully functional as susceptibility factor. Overexpressing SlMLO3 in the Slmlo mutant may provide a better evidence on its eventual role as a functional susceptibility gene.

Interestingly, we noticed that SlMLO4 and SlMLO14, which do not belong to clade $\mathrm{V}$, are up-regulated upon $O$. neolycopersici infection (Figure 3 and Supplementary Figures 4, 5). SlMLO14 is closely related to AtMLO4 and AtMLO11, which are involved in root thigmomorphogenesis (Chen et al., 2009), while SlMLO4 is related to AtMLO7, involved in pollen tube reception (Kessler et al., 2010). In Arabidopsis, mutation of AtMLO4, AtMLO7, and AtMLO11 does not result in PM resistance. Thus, we expected that silencing of SlMLO4 and SlMLO14 in tomato will not lead to PM resistance too. The up-regulated expression of SlMLO4 and SlMLO14 after challenge with O. neolycopersici might be the result of shared regulatory cis-acting elements. We used a $2 \mathrm{~kb}$ region located upstream the starting codon of SlMLO1, SlMLO4, and SlMLO14 coding sequences to search for shared regulatory elements through the online database Plant Care (http://bioinformatics.psb.ugent.be/webtools/plantcare/html/) (Lescot et al., 2002). We found at least five common motifs which are associated with upregulation by multiple biotic and/or abiotic stresses: ABRE (CACGTG), involved in abscisic acid responsiveness, CGTCA- and TGACGmotifs, involved in the MeJA responsiveness, HSE (AAAAAATTC), involved in heat stress responsiveness, and TCA (CCATCTTTTT/GAGAAGAATA) element, involved in salicylic acid response. It is intriguing whether SlMLO4 and SlMLO14 can act as a susceptibility gene to PM. Till now, only clade IV and clade V MLO genes have been studied for their role as a susceptibility gene. To further study these PM-induced non-clade $\mathrm{V} S I M L O$ genes, a complementation test using the Slmlo mutant could be performed.

In conclusion, this study provides a comprehensive characterization of the $M L O$ gene family in tomato by analyzing their genomic structure, expression profile and predicted protein motifs. In tomato, there are $17 \mathrm{MLO}$ genes which can be grouped into six clades. The expression of these $M L O$ genes can be tissue specific and some $M L O$ genes show alternative splicing variants in different tissues. The SlMLO1 in clade $\mathrm{V}$ is confirmed to be the major PM susceptibility factor. In addition, two clade V genes, SlMLO5 and SlMLO8, are suggested to have a partial redundant function, as described in Arabidopsis for AtMLO2, 6, and 12 genes (Consonni et al., 2006). To label an $M L O$ gene as a PM susceptibility gene, it is recommended to combine phylogenetic analysis and expression profile to select candidates of clade IV (for monocot) and V (for dicot) that are induced by PM infection. However, the upregulation of $M L O$ genes outside clade $\mathrm{V}$ in response to $\mathrm{PM}$, as shown in this study and in Pessina et al. (2014), raises the possibility that they may act as susceptibility genes. Finally, the RNAi lines generated in this study are useful materials for further assigning new biological functions to the $M L O$ gene family members.

\section{MATERIALS AND METHODS}

\section{Plant Material, Fungal Material, and Inoculation}

In this study, we used the susceptible $S$. lycopersicum cultivar Moneymaker (MM), the Slmlo1 line and transgenic $\mathrm{T}_{2}$ families in which individual SlMLO gene was silenced via RNAi in MM background. The Slmlo1 mutant (the ol-2 gene) was a natural mutation discovered in the resistant line LC-95 of S. lycopersicum var. cerasiforme. The LC-95 line was crossed with the susceptible tomato S. lycopersicum cv. Super Marmande and the F2 progeny was used for mapping in 1998 (Ciccarese et al., 1998). Later, we introgressed the ol-2 allele into S. lycopersicum cv Moneymaker (MM) by backcrossing and one BC3S2 line homozygous for the ol-2 allele (the tomato Slmlo1 line) was used in the experiment.

The powdery mildew disease assay was performed by artificial inoculation in the greenhouse. For this, the Wageningen isolate of O. neolycopersici (On) was used (Bai et al., 2008). A suspension of $O$. neolycopersici conidia was prepared, by rinsing freshly sporulating leaves of infected tomato plants with tap water. This suspension was immediately sprayed on 1 month-old tomato plants. Ten plants for each of the $\mathrm{T}_{2}$ progenies obtained from the transformation of each silencing construct, 10 Slmlo1 plants and $10 \mathrm{MM}$ plants were used for disease assay. The scoring of powdery mildew symptoms was done 10 days after inoculation, inspecting and collecting the third and fourth true leaves for each plant.

For the evaluation of the expression of the SIMLO gene family, two independent inoculations were set up. In both cases, we used the cultivar MM, four and three biological replicates for each of the three time points $(0,6$, and $10 \mathrm{~h}$ post inoculation -hpi-) during the first and the second inoculation, respectively.

\section{Identification and Cloning of the SIMLO Gene Family}

Putative tomato MLO protein sequences were identified in the Sol Genomics Network (SGN) (http://solgenomics.net/) database by using the BLASTP and TBLASTN algorithms with Arabidopsis AtMLO protein sequences as query. Chromosomal localization, sequences of the corresponding genes and introns/exons boundaries were inferred by annotations from the International Tomato Annotation Group (ITAG).

Aiming at cloning and sequencing the SlMLO gene family from the cultivar MM, total RNA from leaf, root, flower and ripened fruit was isolated (RNeasy ${ }^{\circledR}$ mini kit, Qiagen). The different tissues were collected from five MM plants and pooled together to obtain enough material for the RNA isolation. For each individual SlMLO homolog, two primer pairs specifically amplifying overlapping products of around $800 \mathrm{bp}$ of the predicted coding sequences (CDS) were designed using the Primer3 plus online software (http://www. bioinformatics.nl/cgi-bin/primer3plus/primer3plus.cgi; Rozen and Skaletsky, 2000). The forward primer and the reverse primer of product $\mathrm{A}$ and product $\mathrm{B}$, respectively, are located in the respective UTR regions to ensure the cloning of the complete CDS. A one-step PCR was performed to obtain 
the desired product (SuperScript ${ }^{\circledR}$ III One-Step RT-PCR System, Invitrogen; Supplementary Table 1). Its high sensitivity and specificity ensured the amplification of these very lowly expressed genes. Indeed, a PCR performed on a cDNA obtained with oligo $(\mathrm{dT})_{20}$ primers did not yield any product for many of the homologs under investigation. The use of sequence-specific primers in the one-step PCR, on the other hand, allowed the binding of only the desired mRNA sequences.

Corresponding amplicons were visualized on agarose gel and cloned into the pGEM ${ }^{\circledR}$-T Easy vector (Promega). Recombinant plasmids were sequenced by using universal T7 and SP6 primers.

In order to reveal gene structures and polymorphisms, SlMLO sequences obtained by cloned amplicons were merged using the package Seqman of the software DNASTAR ${ }^{\circledR}$ Lasergene8. The obtained consensus was aligned with the coding region of the SlMLO identified in silico and the corresponding genomic region using the CLC 7.6.1 sequence viewer software (www.clcbio.com).

Finally, for the motif analysis, the MEME (http://meme. nbcr.net/) package was used to predict consensus patterns of consecutive conserved amino acids in the SIMLO proteins deriving from the in silico translation of the cloned transcripts from leaf, root, flower, and fruit of the cultivar MM (Bailey et al., 2015).

\section{Comparative Analysis}

The corresponding SIMLO protein sequences of translated cloned CDS obtained from leaf and flower (in the case of SlMLO12) were used as dataset in the CLC 7.6.1 sequence viewer software (www.clcbio.com) for ClustalW alignment and the obtainment of an UPGMA-based comparative tree (bootstrap value was set equal to 100), together with those of the 15 Arabidopsis AtMLO homologs. Moreover, MLO proteins experimentally shown to be required for PM susceptibility were added, namely pea PsMLO1, barley HvMLO, wheat TaMLO_A1b and TaMLO_B1a, rice OsMLO3, pepper CaMLO2, tobacco NtMLO1, cucumber CsaMLO8, Lotus japonicus LjMLO1, and barrel clover MtMLO1. Moreover, MLO homologs of the Rosaceae species that cluster in clade VII (FvMLO15, MdMLO18, PpMLO9) and VIII (FvMLO13, MdMLO20, and PpMLO13) were included (Supplementary Table 2). The obtained UPGMAcomparative tree was then displayed as circular rooted cladogram with CLC software.

\section{Expression Analysis of the SIMLO Gene Family in Response to O. neolycopersici}

Tissue samples from the third and fourth true leaf of 1 monthold tomato plants were collected immediately before fungal inoculation and at two time points after inoculation (6 and $10 \mathrm{~h})$. The RNA isolation was performed with MagMAX-96 Total RNA Isolation kit (Applied Biosystem), following the manufacturer's instructions. Included in the protocol is a DNase treatment using the TURBO ${ }^{\mathrm{TM}}$ DNase. An aliquot of the RNA isolated was run on denaturing agarose gel to assess its integrity. Purity and concentration were determined by measuring its absorbance at 260 and $280 \mathrm{~nm}$ using the NanoDrop ${ }^{\circledR} 1000 \mathrm{~A}$ spectrophotometer. Following this protocol for RNA isolation, intact and pure RNA was obtained and the concentration was variable between 200 and $250 \mathrm{ng} / \mu \mathrm{l}$.

cDNAs were synthesized by using the SuperScript III firststrand synthesis kit (Invitrogen) using the oligo $(\mathrm{dT})_{20}$ primer, starting from the same amount of RNA $(200 \mathrm{ng} / \mu \mathrm{l})$. Specific primer pairs for each of the $16 \mathrm{SlMLO}$ homologs, amplifying fragments ranging from 70 to $230 \mathrm{bp}$, were designed as described above (Supplementary Table 3). The amplification of single fragments of the expected size for each homolog was verified by agarose gel electrophoresis and by the observation of the melting pick. Four tomato reference genes were tested for expression stability in order to determine which ones could be suitable for normalization of the expression of SIMLO homologs. These included the 60S ribosomal protein L33 (GeneBank number Q2MI79), the elongation factor $1 \alpha$ (GeneBank number X14449), actin (Genebank XP_004236747), and ubiquitin (GeneBank number XP_004248311) (Schijlen et al., 2007; Løvdal and Lillo, 2009). Gene expression stability was assayed with the BestKeeper program (Pfaffl et al., 2004), determining as best reference genes the ribosomal protein L33 and the elongation factor $1 \alpha$. The cDNAs were diluted 10 -fold and used in real-time qPCR with a Bio-Rad CFX96TM thermal cycler. The thermal cycling conditions used were $95^{\circ} \mathrm{C}$ for $1 \mathrm{~min}$, followed by 40 cycles at: $95^{\circ} \mathrm{C}$ for $15 \mathrm{~s}, 60^{\circ} \mathrm{C}$ for $1 \mathrm{~min}$, and $72^{\circ} \mathrm{C}$ for $30 \mathrm{~s}$, followed by a melt cycle of $0.5^{\circ} \mathrm{C}$ increment per min from 65 to $95^{\circ} \mathrm{C}$. Comparable amplification efficiencies between target and reference genes were determined using the LinRegPCR software (Karlen et al., 2007). Normalization was performed according to the $\Delta \Delta \mathrm{C}_{t}$ method (Livak and Schmittgen, 2001). Four biological replicates and two technical replicates were used in this experiment. Student's $t$-tests were applied in order to assess significant differences between the treatments.

\section{SIMLO Family Expression Analysis in Different Tissues}

To analyze $M L O$ gene expression in leaf, root, flower and ripened fruit approximately equal amount of tissues from five MM plants were pooled and used for RNA isolation and cDNA synthesis as described in the previous paragraph. Before using them as templates, cDNAs were diluted 10-fold. Real-time qPCR was performed using the set of primers reported in Supplementary Table 3 to amplify each homolog in the four tissues above mentioned. Elongation factor $1 \alpha$ was used as reference gene. Data analysis was performed according to the $\Delta \mathrm{C}_{t}$ method (Livak and Schmittgen, 2001). Three technical replicates for each sample were performed.

\section{Generation of RNAi Silencing Lines}

Four primer pairs were designed to amplify and clone fragments from SlMLO1, SlMLO3, SlMLO5, and SlMLO8 into the Gateway-compatible vector pENTR D-TOPO (Invitrogen) (Supplementary Table 3). The cloned sequences of the SlMLO1, SlMLO3, SlMLO5, and SlMLO8 genes are highlighted in Supplementary Figure 6. After cloning in E. coli (strain DH5 $\alpha$ ), the kanamycin-resistant colonies were assessed for the presence of constructs by colony PCR. Positive recombinant plasmids were further analyzed by restriction enzyme digestion 
and sequencing. Next, amplicons were transferred by LR recombination reaction into the pHELLSGATE12 vector for hairpin-induced RNAi (Wielopolska et al., 2005) following the instructions provided by the manufacturer (Invitrogen), and cloned again in E. coli DH5 $\alpha$. Bacterial colonies growing on a spectinomycin-containing medium were selected for the presence of the silencing construct by colony PCR and sequencing. Recombinant plasmids were transferred into the AGL1+virG strain of Agrobacterium tumefaciens (Lazo et al., 1991) by electroporation, and transformed bacterial cells were selected on a medium containing $100 \mathrm{mg} / \mathrm{ml}^{-1}$ spectinomycin, $50 \mathrm{mg} / \mathrm{ml}^{-1}$ carbenicillin, and $50 \mathrm{mg} / \mathrm{ml}^{-1}$ chloramphenicol. Single colonies of $A$. tumefaciens were picked and the presence of the insert was confirmed by colony PCR. Ten-fold dilutions of overnight culture from single positive colonies were resuspended in MSO medium (4.3 g/l MS basal salt mixture, $30 \mathrm{~g} / \mathrm{l}$ sucrose, $0.4 \mathrm{mg} / \mathrm{l}$ thiamine, $100 \mathrm{mg} / \mathrm{l}$ myoinositol, $\mathrm{pH} 5.8$ ) to a final $\mathrm{OD}_{600}$ of 0.5 and used for transformation.

The transformation procedure for tomato cotyledons was carried out similarly to the method described by Appiano et al. (2015).

Silencing efficiency was assessed, for each of the four constructs, on 10-20 $\mathrm{T}_{1}$ plants and on selected $\mathrm{T}_{2}$ lines by real-time qPCR, as described for the analysis of the SlMLO gene family expression in response to $O$. neolycopersici. In addition, the $\mathrm{T}_{2}$ lines were assessed for the presence of the NPTII marker gene and the $35 \mathrm{~S}$ promoter by $\mathrm{PCR}$, using the primer pair NPTII_Fw (5'ACTGGGCACAACAGACAATC3 ${ }^{\prime}$ )/NPTII_Rev (5' TCGTCCTGCAGTTCATTCAG $3^{\prime}$ ) and 35S-Fw $\left(5^{\prime}-\right.$ GCTCCTACAAATGCCATCA-3 $\left.{ }^{\prime}\right) / 35$ S-Rev $\quad\left(5^{\prime}\right.$ - GATAGTGG GATTGTGCGTCA- $3^{\prime}$ ), and visualizing the products on agarose gel.

\section{Disease Quantification on Silenced Lines}

$\mathrm{T}_{2}$ lines originating from selfing of $\mathrm{T}_{1}$ plants showing high level of silencing were inoculated with $O$. neolycopersici $(\mathrm{On})$ by spraying 4 weeks old plants with a suspension of conidiospores obtained from freshly sporulating leaves of heavily infected plants and adjusted to a final concentration of $4 \times 10^{4}$ spores $/ \mathrm{ml}$. Inoculated plants were grown in a greenhouse compartment at $20 \pm 2{ }^{\circ} \mathrm{C}$ with $70 \pm 15 \%$ relative humidity and day length of 16 h. Two weeks later, infected tissues from the third and fourth true leaf were visually scored and sampled. Plant and fungal DNAs were extracted by using the DNeasy DNA extraction kit (Qiagen). In total, $15 \mathrm{ng}$ of DNA was used as template for amplification with the primer pair $\mathrm{On}$-Fw $\left(5^{\prime}\right.$-CGCCAAAGACCTAACCAAAA-3') and $O n$-Rev ( $5^{\prime}$-AGCCAAGAGATCCGTTGTTG-3'), designed on $O n$-specific internal transcribed spacer sequences (GenBank accession number EU047564). The tomato Ef1 $\alpha$ primers

\section{REFERENCES}

Acevedo-Garcia, J., Kusch, S., and Panstruga, R. (2014). Magical mystery tour: MLO proteins in plant immunity and beyond. New Phytol. 204, 273-281. doi: 10.1111/nph.12889

Appiano, M., Pavan, S., Catalano, D., Zheng, Z., Bracuto, V., Lotti, C., et al. (2015). Identification of candidate MLO powdery mildew susceptibility genes
(Supplementary Table 3) were used as reference to determine fungal biomass relative to host plant DNA by $\Delta \Delta \mathrm{C}_{t}$ method.

\section{Disease Tests for Microscopic Evaluation in Histological Study}

Spores of the Wageningen isolate of O. neolycopersici grown in a climate chamber at $20 \pm 1^{\circ} \mathrm{C}$, with $70 \pm 10 \% \mathrm{RH}$ and a 16 $\mathrm{h}$ photoperiod were water-sprayed on the third leaf of 1-month old tomato plants of the susceptible tomato cv. MM, the resistant line Slmlo1 and transgenic plants of one $\mathrm{T}_{2}$ family selected by PCR for the presence of the NPTII and 35S marker genes of the RNAi::SlMLO1 silencing construct. The concentration of the spore suspension was $3 \times 10^{5}$ conidia $\mathrm{ml}^{-1}$. After $65 \mathrm{~h}$, a $4 \mathrm{~cm}^{2}$ segment was cut from the inoculated leaves. Three samples were taken from four plants of each genotype and from five plants of the $\mathrm{T}_{2}$ family, bleached in a 1:3 (v/v) acetic acid/ethanol solution and $48 \mathrm{~h}$ later stained in $0.005 \%$ trypan blue as described by Pavan et al. (2008). For each genotype, a total of 90 infection units (IU), defined as a germinated spore that produced, at least, a primary appressorium, were counted. Observations were performed using a Zeiss Axiophot bright field microscope and pictures were taken with an Axiocam ERc5s. For each IU, the number of hyphae, the presence/absence of a primary and secondary haustoria and presence/absence of papillae were recorded.

\section{AUTHOR CONTRIBUTIONS}

Conceived and designed the experiments: ZZ, MA, SP, and VB. Performed the experiments: MA, ZZ, VB. Analyzed the data: MA, ZZ, VB. Contributed reagents/materials/ analysis tools: LR, RV. Wrote and edited the paper: SP, MA, ZZ, AW, and VB.

\section{FUNDING}

The work of $\mathrm{ZZ}$ is supported by the Chinese Academy of Agricultural Sciences Fundamental Research Budget Increment Project (Grant No. 2015ZL008), The Agricultural Science and Technology Innovation Program (Grant No. CAASASTIP-2013-IVFCAAS) and the Merit-based Scientific Research Foundation of the State Ministry of Human Resources and Social Security of China for Returned Overseas Chinese Scholars (Grant No. 2015-192). The work of SP, VB, and LR was supported by the Italian Ministry of University and Research (GenHORT project).

\section{SUPPLEMENTARY MATERIAL}

The Supplementary Material for this article can be found online at: http://journal.frontiersin.org/article/10.3389/fpls.2016. 00380

in cultivated Solanaceae and functional characterization of tobacco NtMLO1. Transgenic Res. 24, 847-858. doi: 10.1007/s11248-015-9878-4

Bai, Y., Pavan, S., Zheng, Z., Zappel, N. F., Reinstädler, A., Lotti, C., et al. (2008). Naturally occurring broad-spectrum powdery mildew resistance in a Central American tomato accession is caused by loss of Mlo function. Mol. Plant Microbe Interact. 21, 30-39. doi: 10.1094/MPMI-21$1-0030$ 
Bai, Y., Van Der Hulst, R., Bonnema, G., Marcel, T. C., Meijer-Dekens, F., Niks, R. E., et al. (2005). Tomato defense to Oidium neolycopersici: dominant OI genes confer isolate-dependent resistance via a different mechanism than recessive oI-2. Mol. Plant Microbe Interact. 18, 354-362. doi: 10.1094/MPMI-18-0354

Bailey, T. L., Johnson, J., Grant, C. E., and Noble, W. S. (2015). The MEME suite. Nucleic Acids Res. 37, W202-W208. doi: 10.1093/nar/gkv416

Berg, J., Appiano, M., Santillán Martínez, M., Hermans, F., Vriezen, W., Visser, R., et al. (2015). A transposable element insertion in the susceptibility gene CsaMLO8 results in hypocotyl resistance to powdery mildew in cucumber. BMC Plant Biol. 15:243. doi: 10.1186/s12870-015-0635-x

Büschges, R., Hollricher, K., Panstruga, R., Simons, G., Wolter, M., Frijters, A., et al. (1997). The barley Mlo gene: a novel control element of plant pathogen resistance. Cell 88, 695-705. doi: 10.1016/S0092-8674(00)81912-1

Chen, Z., Hartmann, H. A., Wu, M. J., Friedman, E. J., Chen, J. G., Pulley, M., et al. (2006). Expression analysis of the AtMLO gene family encoding plantspecific seven-transmembrane domain proteins. Plant Mol. Biol. 60, 583-597. doi: 10.1007/s11103-005-5082-x

Chen, Z., Noir, S., Kwaaitaal, M., Hartmann, H. A., Wu, M. J., Mudgil, Y., et al. (2009). Two seven-transmembrane domain MILDEW RESISTANCE LOCUS O proteins cofunction in arabidopsis root thigmomorphogenesis. Plant Cell 21, 1972-1991. doi: $10.1105 /$ tpc. 108.062653

Ciccarese, F., Amenduni, M., Schiavone, D., and Cirulli, M. (1998). Occurrence and inheritance of resistance to powdery mildew (Oidium lycopersici) in Lycopersicon species. Plant Pathol. 47, 417-419. doi: 10.1046/j.13653059.1998.00254.x

Consonni, C., Humphry, M. E., Hartmann, H. A., Livaja, M., Durner, J., Westphal, L., et al. (2006). Conserved requirement for a plant host cell protein in powdery mildew pathogenesis. Nat. Genet. 38, 716-720. doi: 10.1038/ng1806

Devoto, A., Hartmann, H. A., Piffanelli, P., Elliott, C., Simmons, C., Taramino, G., et al. (2003). Molecular phylogeny and evolution of the plant-specific seventransmembrane MLO family. J. Mol. Evol. 56, 77-88. doi: 10.1007/s00239-0022382-5

Devoto, A., Piffanelli, P., Nilsson, I., Wallin, E., Panstruga, R., von Heijne, G., et al. (1999). Topology, subcellular localization, and sequence diversity of the Mlo family in plants. J. Biol. Chem. 274, 34993-35004. doi: 10.1074/jbc.274.49.34993

Elliott, C., Müller, J., Miklis, M., Bhat, R. A., Schulze-Lefert, P., and Panstruga, R. (2005). Conserved extracellular cysteine residues and cytoplasmic looploop interplay are required for functionality of the heptahelical MLO protein. Biochem. J. 385, 243-254. doi: 10.1042/BJ20040993

Elliott, C., Zhou, F., Spielmeyer, W., Panstruga, R., and Schulze-Lefert, P. (2002). Functional conservation of wheat and rice Mlo orthologs in defense modulation to the powdery mildew fungus. Mol. Plant Microbe Interact. 15, 1069-1077. doi: 10.1094/MPMI.2002.15.10.1069

Feechan, A., Jermakow, A. M., Ivancevic, A., Godfrey, D., Pak, H., Panstruga, R., et al. (2013). Host cell entry of powdery mildew is correlated with endosomal transport of antagonistically acting VvPEN1 and VvMLO to the papilla. Mol. Plant Microbe Interact. 26, 1138-1150. doi: 10.1094/MPMI-04-13-0091-R

Feechan, A., Jermakow, A. M., Torregrosa, L., Panstruga, R., and Dry, I. B. (2008). Identification of grapevine MLO gene candidates involved in susceptibility to powdery mildew. Funct. Plant Biol. 35, 1255-1266. doi: 10.1071/FP08173

Humphry, M., Reinstädler, A., Ivanov, S., Bisseling, T., and Panstruga, R. (2011). Durable broad-spectrum powdery mildew resistance in pea er1 plants is conferred by natural loss-of-function mutations in PsMLO1. Mol. Plant Pathol. 12, 866-878. doi: 10.1111/j.1364-3703.2011.00718.x

Jarosch, B., Kogel, K. H., and Schaffrath, U. (1999). The ambivalence of the barley Mlo locus: mutations conferring resistance against powdery mildew (Blumeria graminis $\mathrm{f}$. sp. hordei) enhance susceptibility to the rice blast fungus Magnaporthe grisea. Mol. Plant Microbe Interact. 12, 508-514.

Jørgensen, I. H. (1992). Discovery, characterization and exploitation of Mlo powdery mildew resistance in barley. Euphytica 63, 141-152. doi: $10.1007 / \mathrm{BF} 00023919$

Karlen, Y., McNair, A., Perseguers, S., Mazza, C., and Mermod, N. (2007). Statistical significance of quantitative PCR. BMC Bioinformatics 8:131. doi: 10.1186/14712105-8-131

Keren, H., Lev-Maor, G., and Ast, G. (2010). Alternative splicing and evolution: diversification, exon definition and function. Nat. Rev. Genet. 11, 345-355. doi: $10.1038 / \operatorname{nrg} 2776$
Kessler, S. A., Shimosato-Asano, H., Keinath, N. F., Wuest, S. E., Ingram, G., Panstruga, R., et al. (2010). Conserved molecular components for pollen tube reception and fungal invasion. Science 330, 968-971. doi: 10.1126/science.1195211

Kim, M. C., Panstruga, R., Elliott, C., Müller, J., Devoto, A., Yoon, H. W., et al. (2002). Calmodulin interacts with MLO protein to regulate defence against mildew in barley. Nature 416, 447-451. doi: 10.1038/416447a

Kumar, J., Hückelhoven, R., Beckhove, U., Nagarajan, S., and Kogel, K. H. (2001). A compromised Mlo pathway affects the response of barley to the necrotrophic fungus Bipolaris sorokiniana (Teleomorph: Cochliobolus sativus) and its toxins. Phytopathology 91, 127-133. doi: 10.1094/PHYTO.2001.91.2.127

Lazo, G. R., Stein, P. A., and Ludwig, R. A. (1991). A DNA transformationcompetent Arabidopsis genomic library in Agrobacterium. Nat. Biotechnol. 9, 963-967. doi: 10.1038/nbt1091-963

Lescot, M., Déhais, P., Thijs, G., Marchal, K., Moreau, Y., Van De Peer, Y., et al. (2002). PlantCARE, a database of plant cis-acting regulatory elements and a portal to tools for in silico analysis of promoter sequences. Nucleic Acids Res. 30, 325-327. doi: 10.1093/nar/30.1.325

Liu, Q., and Zhu, H. (2008). Molecular evolution of the MLO gene family in Oryza sativa and their functional divergence. Gene 409, 1-10. doi: 10.1016/j.gene.2007.10.031

Livak, K. J., and Schmittgen, T. D. (2001). Analysis of relative gene expression data using real-time quantitative PCR and the $2-\Delta \Delta$ CT method. Methods 25, 402-408. doi: 10.1006/meth.2001.1262

Lorek, J., Griebel, T., Jones, A. M., Kuhn, H., and Panstruga, R. (2013). The role of Arabidopsis heterotrimeric G-protein subunits in MLO2 function and MAMP-triggered immunity. Mol. Plant Microbe Interact. 26, 991-1003. doi: 10.1094/MPMI-03-13-0077-R

Løvdal, T., and Lillo, C. (2009). Reference gene selection for quantitative real-time PCR normalization in tomato subjected to nitrogen, cold, and light stress. Anal. Biochem. 387, 238-242. doi: 10.1016/j.ab.2009.01.024

Miklis, M., Consonni, C., Bhat, R. A., Lipka, V., Schulze-Lefert, P., and Panstruga, R. (2007). Barley MLO modulates actin-dependent and actinindependent antifungal defense pathways at the cell periphery. Plant Physiol. 144, 1132-1143. doi: 10.1104/pp.107.098897

Ner-Gaon, H., Leviatan, N., Rubin, E., and Fluhr, R. (2007). Comparative crossspecies alternative splicing in plants. Plant Physiol. 144, 1632-1641. doi: $10.1104 /$ pp. 107.098640

Opalski, K. S., Schultheiss, H., Kogel, K. H., and Hückelhoven, R. (2005). The receptor-like MLO protein and the RAC/ROP family G-protein RACB modulate actin reorganization in barley attacked by the biotrophic powdery mildew fungus Blumeria graminis f.sp. hordei. Plant J. 41, 291-303. doi: 10.1111/j.1365-313X.2004.02292.x

Palusa, S. G., Ali, G. S., and Reddy, A. S. N. (2007). Alternative splicing of premRNAs of Arabidopsis serine/arginine-rich proteins: regulation by hormones and stresses. Plant J. 49, 1091-1107. doi: 10.1111/j.1365-313X.2006.03020.x

Panstruga, R. (2005). Serpentine plant MLO proteins as entry portals for powdery mildew fungi. Biochem. Soc. Trans. 33, 389-392. doi: 10.1042/BST0330389

Panstruga, R., and Schulze-Lefert, P. (2003). Corruption of host seventransmembrane proteins by pathogenic microbes: a common theme in animals and plants? Microbes Infect. 5, 429-437. doi: 10.1016/S1286-4579(03)00053-4

Pavan, S., Jacobsen, E., Visser, R. G. F., and Bai, Y. (2009). Loss of susceptibility as a novel breeding strategy for durable and broad-spectrum resistance. Mol. Breed. 25, 1-12. doi: 10.1007/s11032-009-9323-6

Pavan, S., Zheng, Z., Borisova, M., Van Den Berg, P., Lotti, C., De Giovanni, C., et al. (2008). Map- vs. homology-based cloning for the recessive gene ol-2 conferring resistance to tomato powdery mildew. Euphytica 162, 91-98. doi: 10.1007/s10681-007-9570-8

Pessina, S., Pavan, S., Catalano, D., Gallotta, A., Visser, R. G., Bai, Y., et al. (2014). Characterization of the MLO gene family in Rosaceae and gene expression analysis in Malus domestica. BMC Genomics 15:618. doi: 10.1186/1471-2164$15-618$

Pfaffl, M. W., Tichopad, A., Prgomet, C., and Neuvians, T. P. (2004). Determination of stable housekeeping genes, differentially regulated target genes and sample integrity: bestkeeper - Excel-based tool using pair-wise correlations. Biotechnol. Lett. 26, 509-515. doi: 10.1023/B:BILE.0000019559.84305.47 
Reinstädler, A., Müller, J., Czembor, J. H., Piffanelli, P., and Panstruga, R. (2010). Novel induced mlo mutant alleles in combination with site-directed mutagenesis reveal functionally important domains in the heptahelical barley Mlo protein. BMC Plant Biol. 10:31. doi: 10.1186/1471-2229-10-31

Rozen, S., and Skaletsky, H. (2000). Primer3 on the WWW for general users and for biologist programmers. Methods Mol. Biol. 132, 365-386. doi: 10.1385/159259-192-2:365

Schijlen, E. G. W. M., de Vos, C. H. R., Martens, S., Jonker, H. H., Rosin, F. M., Molthoff, J. W., et al. (2007). RNA interference silencing of chalcone synthase, the first step in the flavonoid biosynthesis pathway, leads to parthenocarpic tomato fruits. Plant Physiol. 144, 1520-1530. doi: 10.1104/pp.107.100305

Schouten, H., Krauskopf, J., Visser, R. F., and Bai, Y. (2014). Identification of candidate genes required for susceptibility to powdery or downy mildew in cucumber. Euphytica 200, 475-486. doi: 10.1007/s10681-014-1216-Z

Seifi, A., Gao, D., Zheng, Z., Pavan, S., Faino, L., Visser, R. F., et al. (2014). Genetics and molecular mechanisms of resistance to powdery mildews in tomato (Solanum lycopersicum) and its wild relatives. Eur. J. Plant Pathol. 138, 641-665. doi: 10.1007/s10658-013-0314-4

Shen, Q., Zhao, J., Du, C., Xiang, Y., Cao, J., and Qin, X. (2012). Genome-scale identification of MLO domain-containing genes in soybean (Glycine max L. Merr.). Genes Genet. Syst. 87, 89-98. doi: 10.1266/ggs.87.89

The 100 Tomato Genome Sequencing Consortium, Aflitos, S., Schijlen, E., De Jong, H., De Ridder, D., Smit, S., et al. (2014). Exploring genetic variation in the tomato (Solanum section Lycopersicon) clade by whole-genome sequencing. Plant J. 80, 136-148. doi: 10.1111/tpj.12616

Tomato Genome Consortium (2012). The tomato genome sequence provides insights into fleshy fruit evolution. Nature 485, 635-641. doi: 10.1038 /nature11119 van Schie, C. C. N., and Takken, F. L. W. (2014). Susceptibility genes 101: how to be a good host. Annu. Rev. Phytopathol. 52, 551-581. doi: 10.1146/annurev-phyto102313-045854

Várallyay, É., Giczey, G., and Burgyán, J. (2012). Virus-induced gene silencing of Mlo genes induces powdery mildew resistance in Triticum aestivum. Arch. Virol. 157, 1345-1350. doi: 10.1007/s00705-012-1286-y

Wielopolska, A., Townley, H., Moore, I., Waterhouse, P., and Helliwell, C. (2005). A high-throughput inducible RNAi vector for plants. Plant Biotechnol. J. 3, 583-590. doi: 10.1111/j.1467-7652.2005.00149.x

Zheng, Z., Nonomura, T., Appiano, M., Pavan, S., Matsuda, Y., Toyoda, H., et al. (2013). Loss of function in Mlo orthologs reduces susceptibility of pepper and tomato to powdery mildew disease caused by Leveillula taurica. PLOS ONE 8:e70723. doi: 10.1371/journal.pone.0070723

Zhou, S. J., Jing, Z., and Shi, J. L. (2013). Genome-wide identification, characterization, and expression analysis of the MLO gene family in Cucumis sativus. Genet. Mol. Res. 12, 6565-6578. doi: 10.4238/2013.december.11.8

Conflict of Interest Statement: The authors declare that the research was conducted in the absence of any commercial or financial relationships that could be construed as a potential conflict of interest.

Copyright $\odot 2016$ Zheng, Appiano, Pavan, Bracuto, Ricciardi, Visser, Wolters and Bai. This is an open-access article distributed under the terms of the Creative Commons Attribution License (CC BY). The use, distribution or reproduction in other forums is permitted, provided the original author(s) or licensor are credited and that the original publication in this journal is cited, in accordance with accepted academic practice. No use, distribution or reproduction is permitted which does not comply with these terms. 